\title{
Modeling and optimization of surface roughness and productivity thru RSM in face milling of AISI 1040 steel using coated carbide inserts
}

\author{
Mohamed Fnides ${ }^{\mathrm{a}}{ }^{*}$, Mohamed Athmane Yallese ${ }^{\mathrm{a}}$, Riad Khattabi ${ }^{\mathrm{a}}$, Tarek Mabrouki ${ }^{\mathrm{b}, \mathrm{c}}$ and \\ François Girardin ${ }^{d}$
}

${ }^{a}$ Mechanics and Structures Research Laboratory (LMS), May 8th 1945 University, P.O. Box 401, 24000 Guelma, Algeria

${ }^{b}$ University of Tunis El Manar, ENIT, 1002 Tunis, Tunisia

${ }^{c}$ LaMCoS, CNRS, INSA-Lyon, UMR5259, Lyon University, F69621, France

${ }^{d}$ Laboratoire Vibrations Acoustique, INSA-Lyon, 25 bis avenue Jean Capelle, F-69621 Villeurbanne Cedex, France

\section{H R O N I C L E}

Article history:

Received October 272016

Received in Revised Format

December 222016

Accepted February 272017

Available online

March 12017

Keywords:

Face milling

RSM

Optimization

Flank wear

Surface roughness and

productivity

\begin{abstract}
A B S T R A C T
The aim of this study is to evaluate the impact of factors such as cutting speed, feed rate, and depth of cut on surface roughness and Material Removed Rate (MRR) when machining in dry face milling AISI 1040 steel with coated carbide inserts GC1030 using the response surface methodology (RSM). For this purpose, a number of machining experiments based on statistical three-factor and three-level factorial experiment designs, completed (L27) with a statistical analysis of variance (ANOVA), were performed in order to develop mathematical models and to identify the significant factors of these technological parameters. Multi-objective optimization procedure for minimizing Ra, Ry and Rz and maximizing MRR using desirability approach has been also implementented. The current study was also carried out to investigate the tool life of the inserts. The models found the relationship between the cutting parameters (Vc, fz and ap) and the studied technological parameters. It has been found that the cutting speed was the most affecting surface roughness which is due to the geometry of the insert which has a scraping edge and enables to obtain low roughness even at important feed rate, followed by the feed rate and the depth of cut at the end. The optimal combination of cutting parameters were cutting speed of $314 \mathrm{~m} / \mathrm{min}$, feed rate of $0.16 \mathrm{~mm} /$ tooth and depth of cut of $0.6 \mathrm{~mm}$ with a composite desirability of 0.924 .
\end{abstract}

(C) 2017 Growing Science Ltd. All rights reserved

\begin{tabular}{lccc} 
Nomenclature & & \\
\hline$V c$ & Cutting speed, $\mathrm{m} / \mathrm{min}$ & ANOVA & Analysis of variance \\
$f z$ & feed rate, $\mathrm{mm} / \mathrm{tooth}$ & $d f$ & Degrees of freedom \\
$a p$ & depth of cut, $\mathrm{mm}$ & $S S$ & Sequential sum of square \\
$a e$ & Radial depth of cut, $\mathrm{mm}$ & $M S$ & Adjusted mean squares \\
$R a$ & arithmetic mean roughness, $\mu \mathrm{m}$ & Cont. $\%$ & Contribution ratio, $\%$ \\
$R y$ & total roughness, $\mu \mathrm{m}$ & $P$ & Probability \\
$R z$ & mean depth of roughness, $\mu \mathrm{m}$ & $R^{2}$ & coefficient of determination \\
$Z$ & Number of tooth & $M R R$ & Material Removed Rate, $\mathrm{mm}^{3} / \mathrm{min}^{2}$ \\
$D$ & Diameter milling cutter, $\mathrm{mm}$ & $V B$ & Flank wear, $\mathrm{mm}$ \\
\hline
\end{tabular}

* Corresponding author Tel: 213-664217394

E-mail: fnides mohamed@yahoo.fr (M. Fnides)

(C) 2017 Growing Science Ltd. All rights reserved. doi: $10.5267 /$ j.. jiec.2017.3.001 


\section{Introduction}

The surface roughness is one of the important performance index. It is also considered as the most useful technological parameters due to its relation to many other mechanical properties such as tool life, capacity of adjustment, wear resistance and tightness (Aouici et al., 2013; Meddour et al., 2015; Bouacha et al., 2014; Panda et al., 2016). Therefore, surface defects play a crucial role in the ability of the part to perform a particular function (Fnides et al., 2013; Bhuyan \& Routara, 2016). These defects have either geometrical and/or physico-chemical nature. In the present paper, only the geometrical defects are concerned. In the optimization study of the surface roughness, for the case of face milling of an aluminum alloy mold 6061 -T6 with coated carbide inserts, Kadirgama et al. (2009) found that the RSM was an effective technique for the trends of the surface roughness analysis with respect to different combinations of cutting parameters (cutting speed, feed per tooth, axial and radial depth of cut).

The optimal parameters that could give a good surface in end milling of titanium alloys using the design method of Taguchi has been evaluated by Khairi et al. (2010); the authors used the analysis of variance (ANOVA) for identifying the significant factors affecting roughness. They found that the most significant factors affecting the surface roughness were mainly the cutting speed $(\mathrm{Vc})$, followed by the type of the tool used, the feed rate (fz) and lastly, the depth of cut (ap). Doniavi et al. (2007) proved that the application of the analysis of variance (ANOVA) showed that the feed rate and cutting speed were the most significant factors on the roughness contrary to the depth of cut. The authors used the response surface methodology (RSM) to develop an empirical model for the prediction of the roughness by choosing the optimum cutting conditions in hard turning. RSM has been used by Oktem et al. (2005) to create an efficient analytical model for surface roughness in terms of cutting parameters: feed rate, cutting speed, axial depth of cut, radial depth of cut and machining tolerance.

Many of other researchers (Kevin et al., 2003; Huang et al., 2001) used the technique of multiple linear regressions to develop a comprehensive empirical model of roughness taking into account several factors such as the feed rate, the hardness of the workpiece, the depth of cut, the cutting speed and their interactions. Recently, Keblouti et al. (2016) analyzed and optimized the influence of coating material of cutting tool and machining parameters on surface roughness, in dry turning of AISI 52100 steel. It is observed that a lower surface roughness value is achieved using the PVD (TiCN/TiN) coated insert compared to the uncoated tool. Aouici et al. (2016) investigated and analyzed the surface roughness of different cutting materials in machining AISI H11. The ANOVA result confirmed that multiple linear regression models predict the surface roughness parameter with a confidence level of $95 \%$.

John (2013) used desirability approach to optimize the advantage characteristics of carbonitrided bushes. The results proved that the optimum combination was found through the use of different methods. Mohapatraa et al. (2017) used two multi objective optimization methods for MRR and surface quality comparison of optimization techniques for MRR and surface roughness in the wire EDM process for gear cutting. He investigated the comparison of the wire EDM phenomenon using the Taguchi quality loss function and the hybrid optimization method. Tebassi et al. (2016) studied how to optimize surface quality, cutting forces and productivity when machining Inconel 718. RSM Box-Cox profiles have been investigated to find mathematical models followed by a desirability approach to optimize Ra, cutting forces, fz and ap.

In the current study, different combinations of material-process and tool have been investigated with the integration of the wear analysis. It intends to study the impact of machining conditions on the surface roughness based on the methodology of response surface for face milling of the AISI 1040 steel with coated carbide insert. Multi-objective optimization procedure allowed minimizing Ra, Ry and $\mathrm{Rz}$ and maximizing MRR using desirability approach has been also approved and the tool life of the inserts were calculated. 


\section{Experimental procedures}

\subsection{Equipments and materials}

In this study, the machining experimental tests are performed under dry conditions using a vertical milling machine (FV 1.5) of the company PMO (Almo) running at $5 \mathrm{KW}$.

The workpiece material used in this investigation is a commercially available AISI 1040 steel grade with the following dimensions: $405 \mathrm{~mm}$ X 73mm X 73mm. equivalent with the nuance C35 (NF EN 10027-1) at a better aptitude for the heat treatments. As for parts, they are fairly subjected to shocks and requiring good resistance, they were: gears, endless screw, axes, pinions, nuts and bolts, forging mill (levers, Arbors......). The chemical composition and mechanical properties are given respectively in Table 1 and Table 2.

Table 1

Chemical composition of AISI 1040 steel on \%

\begin{tabular}{cccccc}
\hline $\mathrm{C}$ & $\mathrm{S}$ & $\mathrm{Mn}$ & $\mathrm{P}$ & $\mathrm{Si}$ & $\mathrm{Mo}$ \\
\hline $0.37-0,44$ & $=<0.035$ & $0.50-0,80$ & $=<0.035$ & $0.40 \mathrm{maxi}$ & $=<0.10$ \\
\hline
\end{tabular}

Table 2

Mechanical characteristics of AISI 1040 steel

\begin{tabular}{cccc}
\hline $\mathrm{Rm}, \mathrm{N} / \mathrm{mm}^{2}$ & $\mathrm{Re}, \mathrm{N} / \mathrm{mm}^{2}$ & $\mathrm{~A}, \%$ & Hardness \\
\hline $530 / 580$ & $260 / 320$ & $16 / 17$ & mini 54 HRC \\
\hline
\end{tabular}

Coated carbide inserts with PVD applied unique -layer TiAlN coating of 3.5 micrometer thickness were employed for the machining experiments.- ISO tool designation GC1030 (R245-12 T3-EPL) from Sandvik Coromant tool manufacturer - The specification of the inserts was wiper edge length (scraping edge) $\mathrm{BS}=2.1 \mathrm{~mm}$ (Fig. 1). This insert presents first choice in end milling and for sticky materials, e.g. low-carbon steel.

The milling cutter used in this experiment was a CoroMill 245 cutter which has a capacity for 5 inserts designed and provided by Sandvik Coromant (R245-100Q32-12L). Fig. 1 shows the geometry of the cutting inserts and the milling cutter used for all experiments.

A 2D roughness meter $\mathrm{Sj}$ - 201p (Mitutoyo) was selected to measure surface roughness criteria (Ra: The arithmetic average roughness, Ry: The total roughness and Rz: height of irregularities). It consisted of a diamond point (probe) with a $5 \mu \mathrm{m}$ radius and moves linearly on the working surface. The length examined was $4.0 \mathrm{~mm}$ with a basic cut-off of $0.8 \mathrm{~mm}$, these measurements were repeated three times. The average value of these results was calculated. All roughness measurements have been obtained directly on the tool machine without disassembling the workpiece. On the other hand the analysis of the surface roughness was done using both profiles and 3D topographies of the generated surfaces (Alti surf 500). (See Fig. 1).

For the wear tests, the cutting speed Vc and the feed rate fz have been considered as the parameters showing more influence on this phenomenon (Patel et al., 2006; Richetti et al., 2004; Da Silvaa et al., 2011; Aouici et al., 2014). For lows and intermediates cutting speed and feed rate, the wear occurs at a much longer length of cut corresponding of $120000 \mathrm{~mm}$ (300 machining pass). Subsequently, it was important to take severe cutting conditions, such as $\mathrm{Vc}=439.6 \mathrm{~m} / \mathrm{min}(\mathrm{n}=1400 \mathrm{rpm}) ; \mathrm{fz}=0.114$ $\mathrm{mm} /$ tooth $(\mathrm{Vf}=800 \mathrm{~mm} / \mathrm{min})$; ap $=0.6 \mathrm{~mm}$. The tool life rejection criterion was flank wear, $\mathrm{VB}=0.3$ $\mathrm{mm}$. Flank wear was measured at various intervals at the end of each pass (i.e., after cutting tool moves along a complete length of a workpiece). Relevant images of the worn tools were selected and captured with the microscope (Standard gage- Visual 250) equipped with (Visual Gage 2.2.0) software (Fig. 1). 


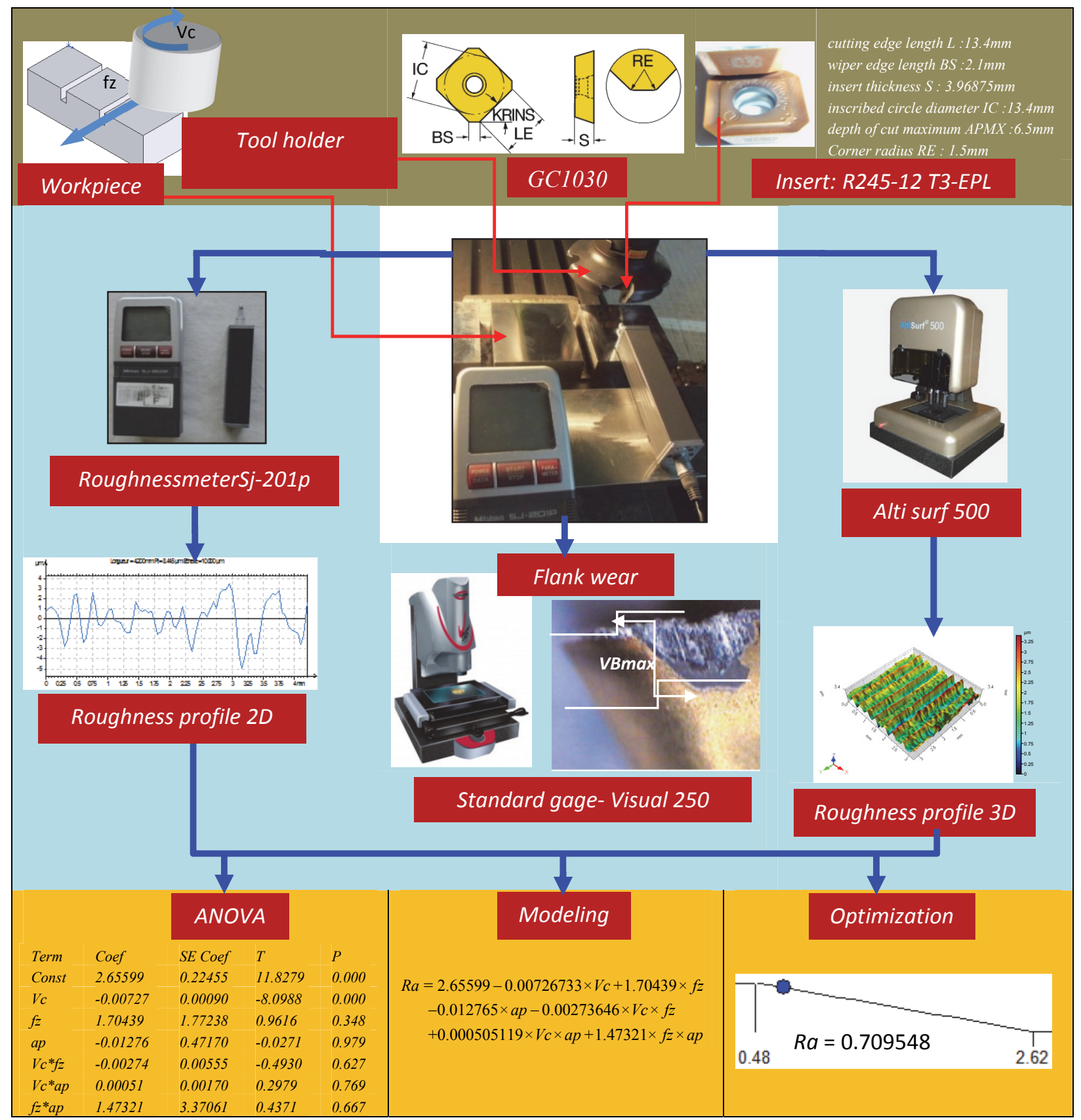

Fig. 1. Illustration of measured surface roughness and tool wear

\subsection{Experiment design}

Cutting experiments are planned using statistical three-level full factorial experimental design and conducted considering three cutting parameters: cutting speed (Vc), feed rate (fz), depth of cut (ap). Overall $33=27$ tests are carried out. Low-middle-high level of cutting parameters in cutting space for three-level full factorial experimental design is shown in Table 3.

Table 3

Low-middle-high levels of cutting parameters in three-level full factorial design of experiment

\begin{tabular}{ccccc}
\hline \multirow{2}{*}{ Factors } & \multirow{2}{*}{ Symbol } & \multicolumn{3}{c}{ Levels } \\
\cline { 3 - 5 } & & Level 1 & Level 2 & Level 3 \\
\hline Cutting speed $\mathrm{m} / \mathrm{min})$ & $\mathrm{Vc}$ & 78 & 157 & 314 \\
Feed rate $(\mathrm{mm} /$ tooth) & fz & 0.04 & 0.08 & 0.16 \\
Depth of cut (mm) & ap & 0.2 & 0.4 & 0.6 \\
\hline
\end{tabular}




\subsection{Response surface methodology}

The response surface methodology (RSM) (Bouzid et al., 2014a; Aouici et al., 2014; Hessainia et al., 2015; Bhaumik \& Maity, 2017; Nayak et al., 2017) is both a statistical and a mathematical technique that is useful for modeling and analyzing problems in which responses can be affected by several variables.

ANOVA tables show the DF, SS, MS, F-VAL, P-VAL in addition to the percentage contribution of each factor and the coefficients of regression mathematical models estimated for Ra, Ry, Rz criteria and MRR, the aim is to analyze the main effect as well as the interactions (Fnides et al., 2009). To calculate constants and coefficients of mathematical models, the Minitab software has been used and characterized by the Analysis of Variance: ANOVA, multiple regression and Response Surface Methodology (RSM). In the current study, the relationship between the cutting conditions and the technology parameters is given by Eq. (1).

$$
Y=\phi(\mathrm{Vc}, f z, a p)
$$

where $Y$ is the desired machinability (roughness, forces, etc.) and $\phi$ is the response function. The approximation of $Y$ is proposed by using a General Regression with interaction terms, which is suitable for studying the main effects of process parameters on machinability characteristics.

\section{Results and discussion}

In Table 4, the experimental values of different criteria surface roughness (Ra, Ry, and Rz) and the Material Removed Rate are shown. These values were obtained by using various combinations of elements of the cutting regime elements (cutting speed, feed per tooth and depth of cut) according to 33 full factorial design.

Table 4

Experimental data for AISI 1040 steel

\begin{tabular}{|c|c|c|c|c|c|c|c|}
\hline \multirow[b]{2}{*}{ Runs } & \multicolumn{3}{|c|}{ Factors } & \multicolumn{4}{|c|}{ Responses } \\
\hline & $\begin{array}{l}\mathrm{Vc}, \\
\mathrm{m} / \mathrm{min}\end{array}$ & $\begin{array}{c}\mathrm{fz}, \\
\mathrm{mm} / \text { tooth }\end{array}$ & $\begin{array}{l}\text { ap, } \\
\mathrm{mm}\end{array}$ & $\begin{array}{l}\mathrm{Ra}, \\
\mu \mathrm{m}\end{array}$ & $\begin{array}{l}\text { Ry, } \\
\mu \mathrm{m}\end{array}$ & $\begin{array}{l}\mathrm{Rz}, \\
\mu \mathrm{m}\end{array}$ & $\begin{array}{l}\text { MRR, } \\
\mathrm{Im}^{3} / \mathrm{min}\end{array}$ \\
\hline 1 & 78 & 0.04 & 0.2 & 2.23 & 13.84 & 12.18 & 730 \\
\hline 2 & 78 & 0.04 & 0.4 & 2.29 & 15.12 & 12.22 & 1460 \\
\hline 3 & 78 & 0.04 & 0.6 & 2.32 & 14.86 & 12.66 & 2190 \\
\hline 4 & 78 & 0.08 & 0.2 & 2.37 & 12.93 & 12.22 & 1460 \\
\hline 5 & 78 & 0.08 & 0.4 & 2.4 & 15.83 & 12.83 & 2920 \\
\hline 6 & 78 & 0.08 & 0.6 & 2.42 & 16.05 & 13.09 & 4380 \\
\hline 7 & 78 & 0.16 & 0.2 & 2.58 & 16.82 & 13.65 & 2920 \\
\hline 8 & 78 & 0.16 & 0.4 & 2.6 & 18.67 & 14.61 & 5840 \\
\hline 9 & 78 & 0.16 & 0.6 & 2.62 & 20.55 & 15.47 & 8760 \\
\hline 10 & 157 & 0.04 & 0.2 & 1.5 & 7.89 & 7.47 & 1460 \\
\hline 11 & 157 & 0.04 & 0.4 & 1.54 & 8.16 & 7.64 & 2920 \\
\hline 12 & 157 & 0.04 & 0.6 & 1.55 & 8.17 & 7.92 & 4380 \\
\hline 13 & 157 & 0.08 & 0.2 & 1.59 & 8.56 & 7.68 & 2920 \\
\hline 14 & 157 & 0.08 & 0.4 & 1.6 & 8.57 & 7.74 & 5840 \\
\hline 15 & 157 & 0.08 & 0.6 & 1.61 & 9.3 & 8.28 & 8760 \\
\hline 16 & 157 & 0.16 & 0.2 & 1.62 & 9.84 & 7.86 & 5840 \\
\hline 17 & 157 & 0.16 & 0.4 & 1.64 & 10.22 & 8.62 & 11680 \\
\hline 18 & 157 & 0.16 & 0.6 & 1.65 & 11.04 & 9.38 & 17520 \\
\hline 19 & 314 & 0.04 & 0.2 & 0.5 & 3.27 & 2.73 & 2920 \\
\hline 20 & 314 & 0.04 & 0.4 & 0.48 & 3.71 & 3.01 & 5840 \\
\hline 21 & 314 & 0.04 & 0.6 & 0.51 & 2.85 & 3.05 & 8760 \\
\hline 22 & 314 & 0.08 & 0.2 & 0.55 & 2.92 & 3.81 & 5840 \\
\hline 23 & 314 & 0.08 & 0.4 & 0.6 & 3.32 & 3.14 & 11680 \\
\hline 24 & 314 & 0.08 & 0.6 & 0.62 & 3.77 & 3.3 & 17520 \\
\hline 25 & 314 & 0.16 & 0.2 & 0.65 & 3.7 & 3.36 & 11680 \\
\hline 26 & 314 & 0.16 & 0.4 & 0.76 & 3.35 & 3.74 & 23360 \\
\hline 27 & 314 & 0.16 & 0.6 & 0.82 & 4.83 & 4.17 & 35040 \\
\hline
\end{tabular}




\subsection{Analysis of variance (ANOVA)}

\subsubsection{Analysis of variance (ANOVA) for $R a, R y$ and $R z$}

In the 1930 this method was developed by Sir Ronald Fisher. ANOVA is a statistically objective based decision-making tool for detecting any differences in average performance of groups of items tested (Eyup et al., 2006). The analysis of variance (ANOVA) of the criteria surface roughness $R a, R z$ and $R y$ respectively indicated in Tables (5-7). These numbers show that the cutting speed $(V c)$ is the most influential factor on the surface roughness followed by the feed rate $(f z)$ and finally the depth of cut (ap) with a negligible contribution. The contribution of $(V c)$ on $R a, R y$ and $R z$ are respectively $96.05 \%, 86.75 \%$ and $92.21 \%$, for feed per tooth (fz) it was $1.5 \%, 3.52 \%$ and $1.88 \%$, finally the depth of cut (ap) with contributions of $0.10 \%, 0.95 \%$ and $0.49 \%$. We have noted, on the contrary, of what is known that the effect of the cutting speed is superior to the feed rate, which is due to the geometry of the insert which has a scraping edge, which enables to obtain low roughness even at important feed rate, as Khairi et al. (2010) had found.

\section{Table 5}

Analysis of variance for the surface roughness $R a$

\begin{tabular}{ccccccc}
\hline Source & DF & SS & MS & F & P & Cont $\%$ \\
\hline Regression & 6 & 14.4889 & 2.4148 & 118.613 & 0.0000 & $97.26 \%$ \\
Vc & 1 & 14.2278 & 1.3353 & 65.591 & 0.0000 & $95.51 \%$ \\
fz & 1 & 0.2167 & 0.0188 & 0.925 & 0.3477 & $1.4 \%$ \\
ap & 1 & 0.0338 & 0.0000 & 0.001 & 0.9786 & $0.2 \%$ \\
Vc*fz & 1 & 0.0049 & 0.0049 & 0.243 & 0.6273 & $0.032 \%$ \\
Vc*ap & 1 & 0.0018 & 0.0018 & 0.089 & 0.7688 & $0.012 \%$ \\
fz*ap & 1 & 0.0039 & 0.0038 & 0.191 & 0.6667 & $0.026 \%$ \\
Error & 20 & 0.4072 & 0.0203 & & & \\
Total & 26 & 14.8961 & & & & \\
\hline
\end{tabular}

\section{Table 6}

Analysis of variance for the surface roughness $R y$

\begin{tabular}{ccccccc}
\hline Source & DF & SS & MS & F & P & Cont $\%$ \\
\hline Regression & 6 & 715.982 & 119.330 & 45.3023 & 0.0000 & $93.14 \%$ \\
Vc & 1 & 666.773 & 24.694 & 9.3746 & 0.0061 & $86.74 \%$ \\
fz & 1 & 27.724 & 5.458 & 2.0719 & 0.1655 & $3.60 \%$ \\
ap & 1 & 7.540 & 1.277 & 0.4848 & 0.4942 & $0.98 \%$ \\
Vc*fz & 1 & 9.344 & 9.344 & 3.5474 & 0.0742 & $1.21 \%$ \\
Vc*ap & 1 & 2.668 & 2.668 & 1.0128 & 0.3262 & $0.34 \%$ \\
fz*ap & 1 & 1.933 & 1.933 & 0.7338 & 0.4018 & $0.25 \%$ \\
Error & 20 & 52.682 & 2.634 & & & \\
Total & 26 & 768.663 & & & & \\
\hline
\end{tabular}

\section{Table 7}

Analysis of variance for the surface roughness $R z$

\begin{tabular}{ccccccc}
\hline Source & DF & SS & MS & F & P & Cont $\%$ \\
\hline Regression & 6 & 430.403 & 71.7338 & 66.5546 & 0.0000 & $95.23 \%$ \\
Vc & 1 & 416.738 & 25.2347 & 23.4128 & 0.0001 & $92.20 \%$ \\
fz & 1 & 8.502 & 0.7966 & 0.7391 & 0.4001 & $1.88 \%$ \\
ap & 1 & 2.247 & 0.1756 & 0.1629 & 0.6907 & $0.49 \%$ \\
Vc*fz & 1 & 1.462 & 1.4619 & 1.3563 & 0.2578 & $0.32 \%$ \\
Vc*ap & 1 & 0.586 & 0.5856 & 0.5433 & 0.4696 & $0.13 \%$ \\
fz*ap & 1 & 0.868 & 0.8680 & 0.8054 & 0.3801 & $0.19 \%$ \\
Error & 20 & 21.556 & 1.0778 & & & \\
Total & 26 & 451.959 & & & & \\
\hline
\end{tabular}


The contributions of interactions ( $\mathrm{Vc} \times \mathrm{fz}, \mathrm{Vc} \times$ ap and $\mathrm{fz} \times \mathrm{ap})$ are respectively $(0.032 \%, 0.012 \%, 0.026 \%)$, $(1.21 \%, 0.34 \%, 0.25 \%)$ and $(0.32 \%, 0.13 \%, 0.19 \%)$ on $R a, R y$ and $R z$. The main effect diagram shows that the cutting speed has the most influential factor on the criteria surface roughness $R a$ since it has the greatest slope, followed by the feed per tooth and finally the effect of depth of cut does not have a significant impact compared to cutting speed and feed (Fig. 2a). It is clear from Fig. 2b that interactions diagrams of cutting parameters have no significant effects on criteria surface roughness (Ra) because the lines do not intersect.

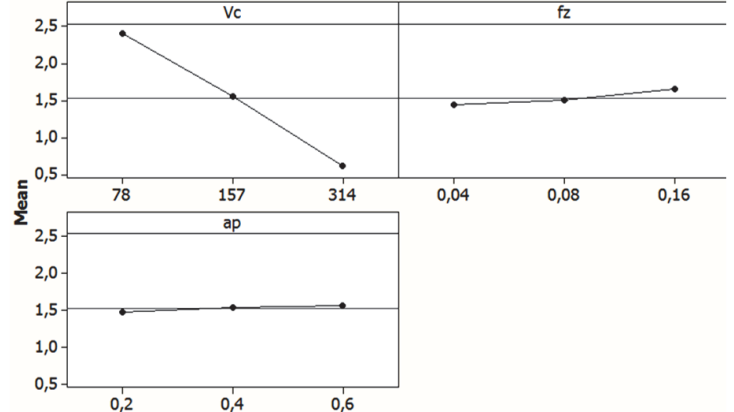

(a)

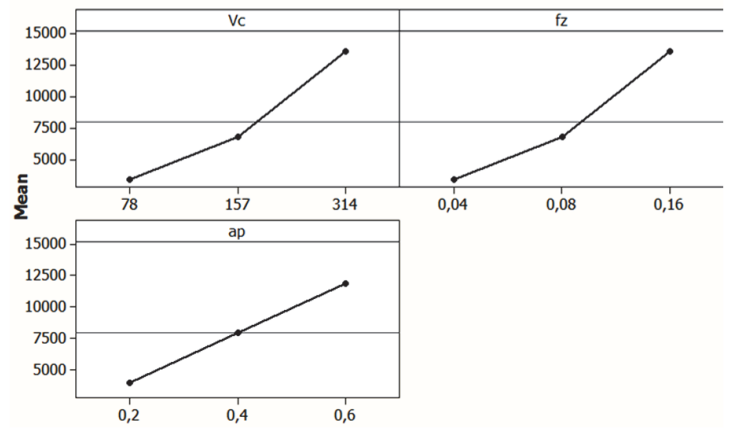

(c)

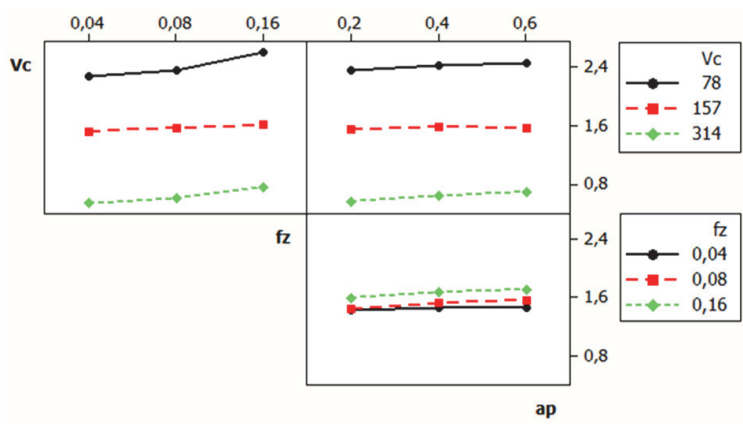

(b)

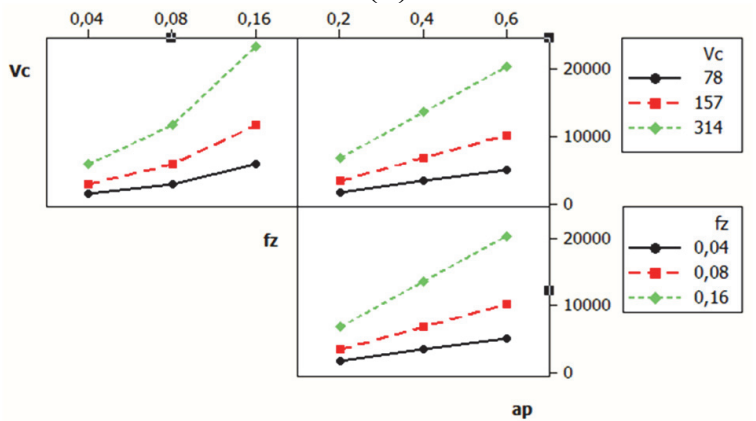

(d)

Fig. 2. Main plot effects and interactions plot for $R a(a . b), M R R(c . d)$

\subsubsection{Analysis of variance (ANOVA) for MRR}

The Material Removed Rate in milling operations is the volume of material/metal that is removed per unit time in $\mathrm{mm} 3 / \mathrm{min}$. The study of this parameter is important: the goal is to manufacture low cost, high quality products in short time (Fnides et al., 2013; Bouzid et al., 2014a). The value of Material Removed Rate was calculated by the following Eq. (2).

$$
\operatorname{MRR}\left(\mathrm{mm}^{\wedge} 3 / \mathrm{mim}\right)=a p(\mathrm{~mm}) \times a e(\mathrm{~mm}) \times f z(\mathrm{~mm} / \text { tooth }) \times Z \times \frac{V c(\mathrm{~m} / \mathrm{mim}) \times 1000}{\pi \times D(\mathrm{~mm})}
$$

Table 8

Analysis of variance for Material Removed Rate

\begin{tabular}{ccccccc}
\hline Source & DF & SS & MS & F & P & Cont $\%$ \\
\hline Regression & 6 & 1560921559 & 260153593 & 224.149 & 0.0000000 & $98.53 \%$ \\
Vc & 1 & 487424660 & 46421396 & 39.997 & 0.0000036 & $30.76 \%$ \\
fz & 1 & 487425867 & 46252592 & 39.851 & 0.0000037 & $30.76 \%$ \\
ap & 1 & 284331756 & 35432272 & 30.529 & 0.0000208 & $17.94 \%$ \\
Vc*fz & 1 & 139264189 & 139264189 & 119.991 & 0.0000000 & $8.79 \%$ \\
Vc*ap & 1 & 81237643 & 81237643 & 69.995 & 0.0000001 & $5.13 \%$ \\
fz*ap & 1 & 81237644 & 81237644 & 69.995 & 0.0000001 & $5.13 \%$ \\
Error & 20 & 23212508 & 1160625 & & & \\
Total & 26 & 1584134067 & & & & \\
\hline
\end{tabular}


Table 8 shows the results of the analysis of variance (ANOVA) for the Material Removed Rate, the analysis (ANOVA) shows that the cutting speed and the feed per tooth are the most significant factors. For their contributions are $30.76 \%$ for both parameters, followed by the depth of cut with a contribution of $17 \%$. All of the interactions (Vc $\times f z, V c \times a p$ and $f z \times a p)$, have significant effects on the Material Removed Rate. Respectively, their contributions are $8.79 \%, 5.13 \%$ and $5.13 \%$. For the main effects plot, we see that the three parameters (Vc, fz and ap) have some influences on the Material Removed Rate (Fig. 2c). Fig. 2d shows the interaction plot of cutting parameters for MRR.

\subsection{Modeling of $R a, R y, R z$ and $M R R$}

Regression analysis is used to investigate and model the relationship between a response variable and one or more predictors. RSM is a combination of mathematical and statistical techniques which is useful for the modeling and analysis of the problem. It determines the suitable approximation for the true functional relationship between the response and the set of independent variables (Myers et al., 2002) and it is commonly approximated by polynomial functions where models are obtained by conducting small number of experiments using design of experiment (Sahoo et al., 2014). According to Hessainia et al. (2013); Bouzid et al. (2014b), the correlations between the factors and the performance measures were modeled by linear regressions. Mathematical models were developed using the multiple regression

method. Ra, Ry, Rz and MRR are successively given by Eqs. (3- 6), their coefficients of determination $\mathrm{R}^{2}$ are respectively $97.27 \%, 93.15 \%, 95.23 \%$ and $98.53 \%$.

$$
\begin{aligned}
R a= & 2.65599-0.00726733 \times \mathrm{Vc}+1.70439 \times \mathrm{fz}-0.012765 \times \mathrm{ap} \\
& -0.00273646 \times \mathrm{Vc} \times \mathrm{fz}+0.000505119 \times \mathrm{Vc} \times \mathrm{ap}+1.47321 \times \mathrm{fz} \times \mathrm{ap} \\
R^{2}= & 97.27 \%, \quad R^{2}(\mathrm{adj})=96.45 \%, \quad R^{2}(\mathrm{pred})=94.77 \% \\
R y= & 13.3783-0.0315938 \times V c+29.1751 \times f z+3.76226 \times a p \\
& -0.120222 \times V c \times f z-0.0196253 \times V c \times a p+32.8423 \times f z \times a p \\
R^{2} & =93.15 \%, \quad R^{2}(\mathrm{adj})=91.09 \%, \quad R^{2}(\mathrm{pred})=87.33 \% \\
R z & =13.1258-0.0319381 \times V c+11.1464 \times f z+1.39511 \times a p \\
& -0.0475516 \times V c \times f z-0.00919462 \times V c \times a p+22.0089 \times f z \times a p \\
R^{2} & =95.23 \%, \quad \mathrm{R}^{2}(\mathrm{adj})=93.80 \%, \quad \mathrm{R}^{2}(\mathrm{pred})=91.28 \% \\
M R R & =7927.21-43.31 \times V c-84934.4 \times F z-19818 \times a p \\
+ & 464.12 \times V c \times f z+108.295 \times V c \times a p+212917 \times f z \times a p \\
R^{2}= & 98.53 \%, R^{2}(\mathrm{adj})=98,10 \%, R^{2}(\mathrm{pred})=94,79 \%
\end{aligned}
$$

These equations can be used to calculate the Ra and MRR from cutting parameters. For Residuals plot for Ra: normal probability plot, A Histogram of the Residuals, Residuals Versus Fitted Values and Residuals Versus Order of Data are represented respectively in Fig. 3a, Fig. 3b, Fig. 3c and Fig. 3d. We notice a goodness of model fit in regression and ANOVA and the normality assumption is valid.

Finally, the curves in Figs. (4-5) are used to compare the predicted values (provided by the model) of the criteria surface roughness Ra, and Material Removed Rate with the experimental values in order to evaluate the fit of the model. The analysis showed a good correlation between the two curves (Sahoo et al., 2014). The experimental and predicted values are very close to each other. Thus, the developed mathematical models can effectively be utilized for prediction of surface roughness. 
(a)

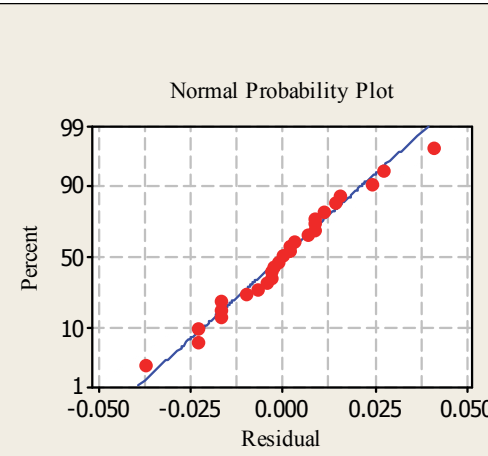

Residual Plots for Ra
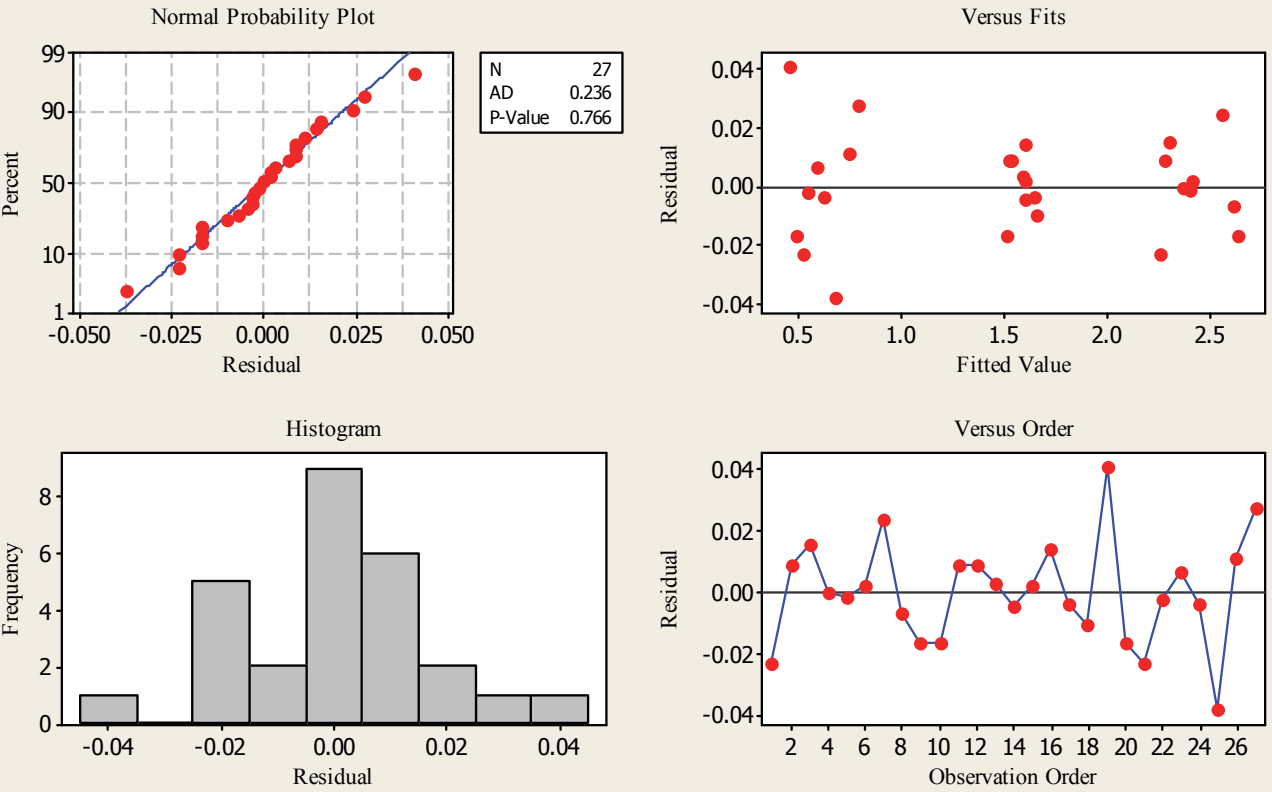

(c)

Fig. 3. Residual plots for Ra

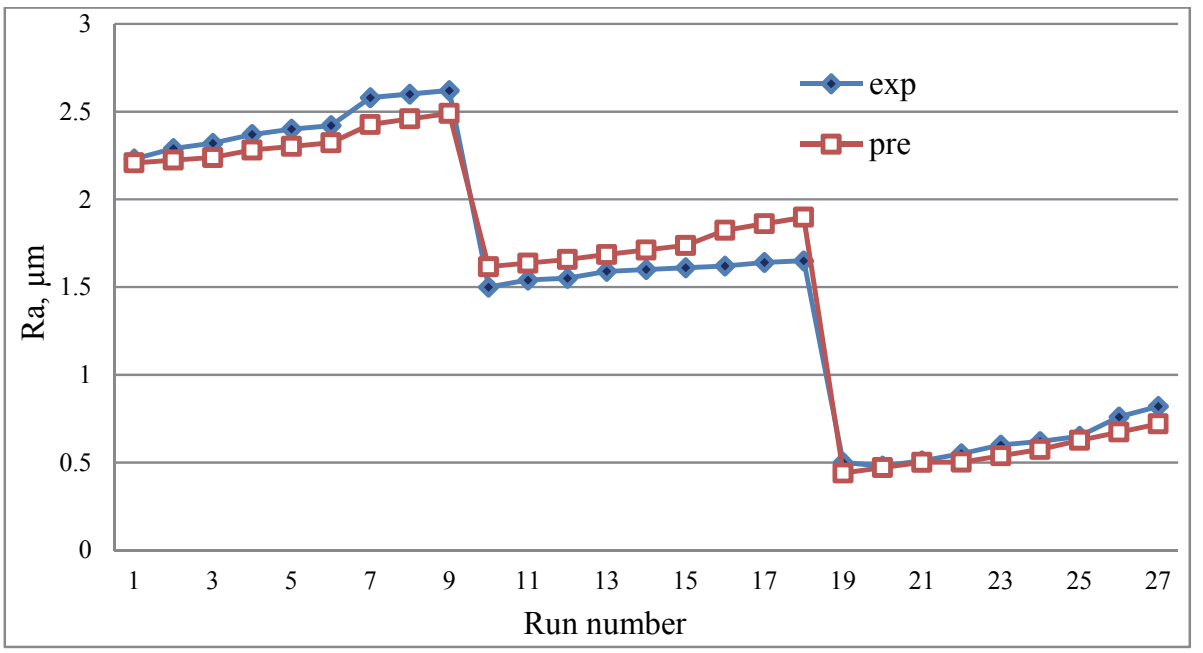

Fig. 4. Comparison between the predicted (pre) and measured (exp) values for Ra

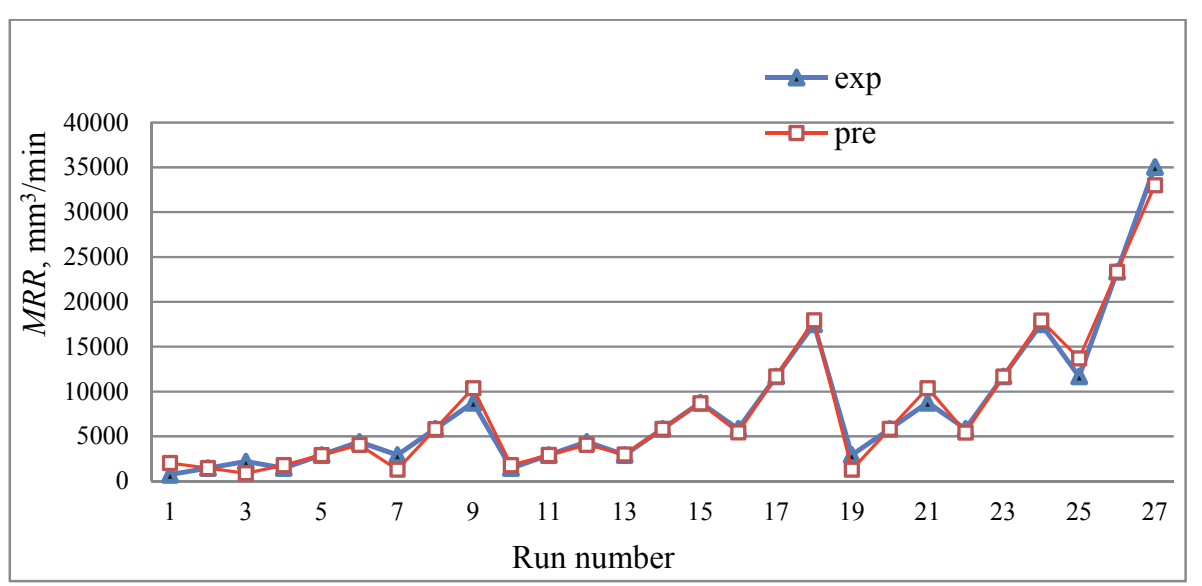

Fig. 5. Comparison between the predicted (pre) and calculated (exp) values for $M R R$ 


\subsection{Response surface and contour plots of Ra and MRR}

RSM determines the suitable approximation for the true functional relationship between the response and the set of independent variables (Barua et al., 2010). The 3D response surface (Fig. 6) shows that the increase in the cutting speed decreases the criteria surface roughness Ra by increasing against the feed per tooth and increasing the surface roughness. Depth of cut has a small influence. Therefore, the better roughness are obtained by applying a low feed per tooth and a high cutting speed. These figures were obtained using response surface methodology according to their mathematical models. On the other hand, contour graphs (Fig. 7) allow visualizing the response surface and establishing the response values. It shows the relationship between a responses value $(\mathrm{Ra})$ and the factors (Vc, fz and ap) from a model equation. The points having the same response are joined to generate the contour lines of constant responses. The (3D) response surface plot of the Material Removed Rate MRR according to the factors of the experiment is shown in Fig. 8. This figure shows that the slope of the feed per tooth (fz) and the cutting speed ( $\mathrm{Vc}$ ) are higher, implying that these factors have an important influence on the Material Removed Rate followed by the depth of cut (ap). On the other hand, the contour graphs (Fig. 9) allow visualizing the response surface and establishing the response values.

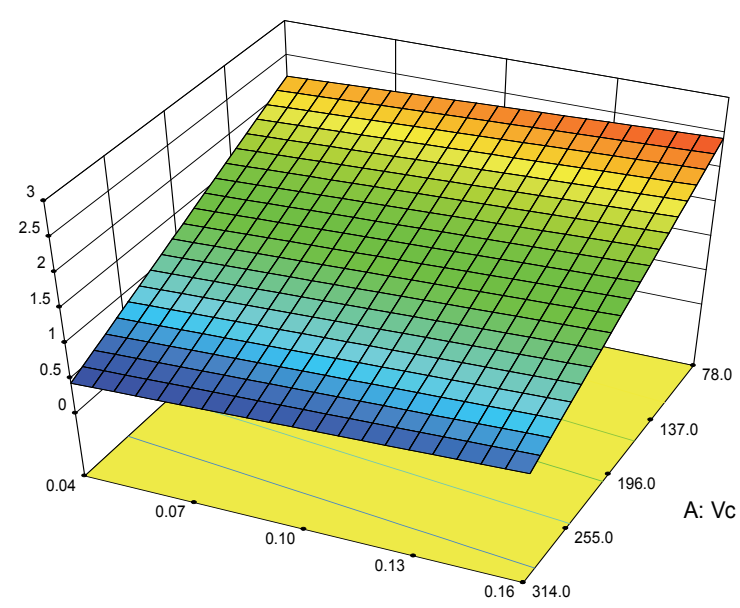

(a)

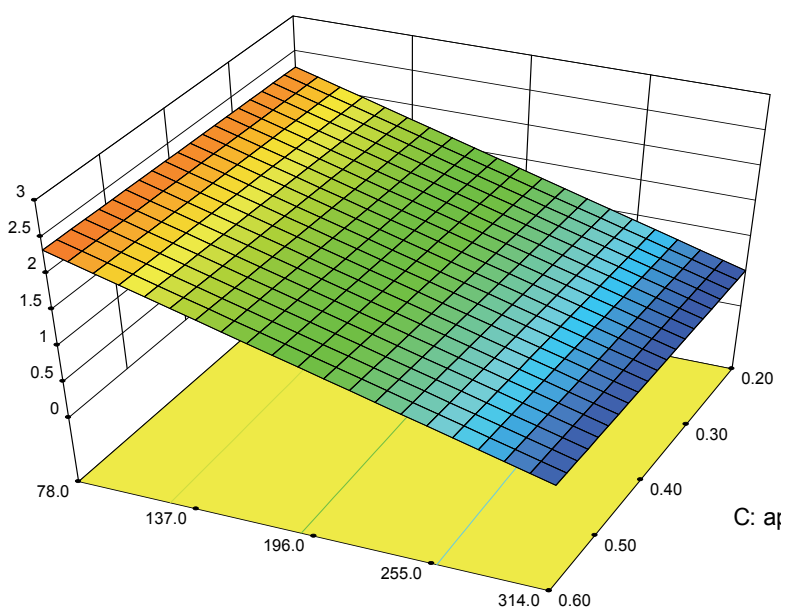

(b)

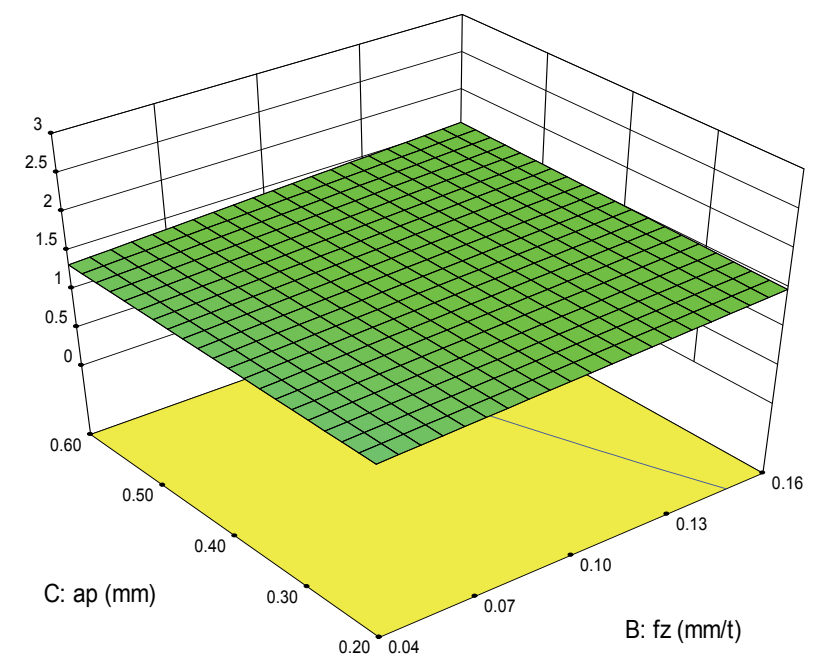

(c)

Fig. 6. Response surface for $\mathrm{R} a$ as a function of (Vc, fz), (Vc, ap) and (ap, fz) 

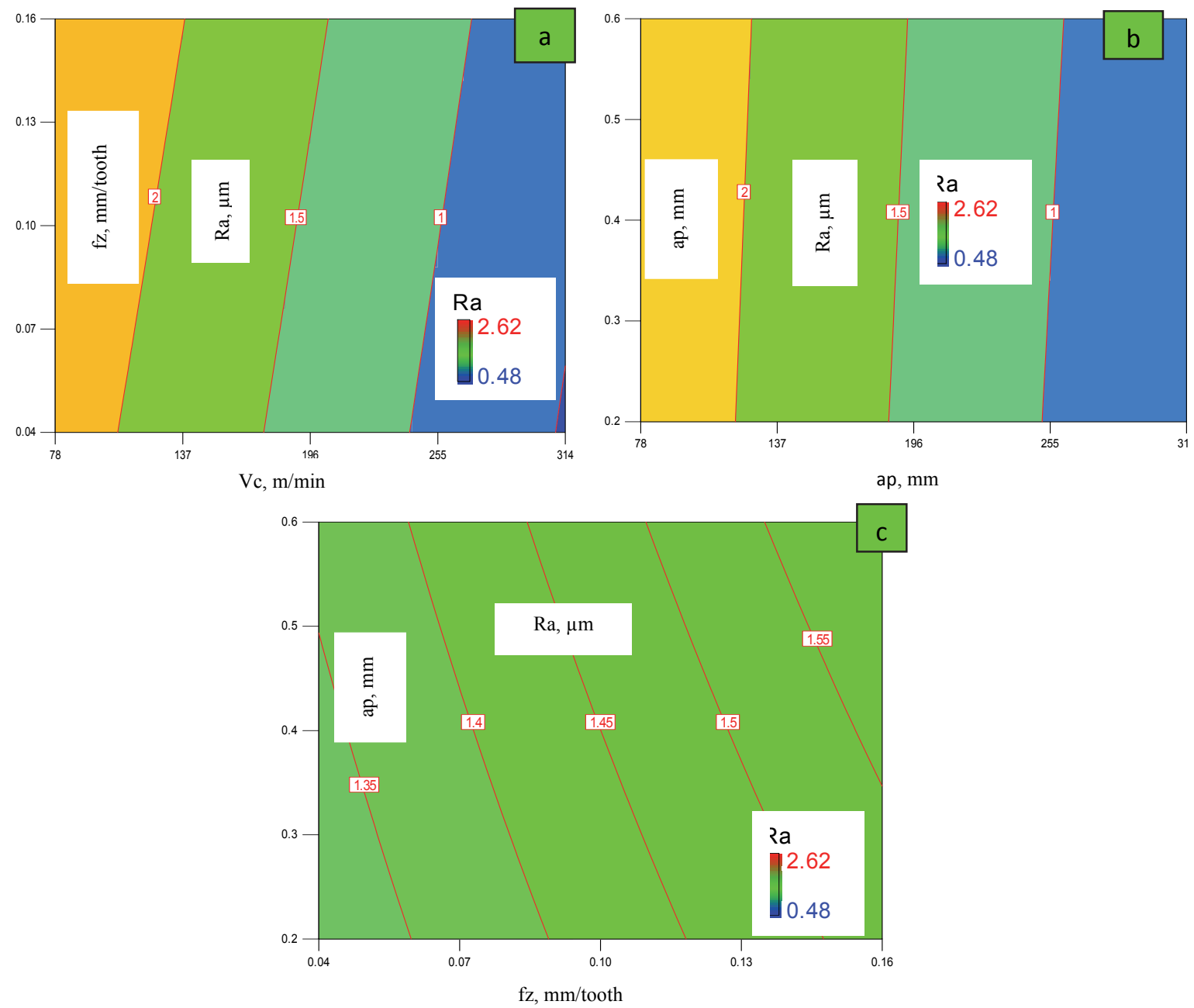

Fig. 7. Contour plot of $\mathrm{R} a=\mathrm{f}(\mathrm{V} c$, fz, ap)

\subsection{Multi-response optimization using desirability approach}

Optimization methods have to be used to obtain the optimum machining conditions for milling operations using surface roughness and Material Removed Rate as responses. During the optimization process, the aim is to minimize the criteria surface roughness $R a, R z$ and $R y$ and Maximize the MRR. The desirability approach is a popular method that assigns a "score" to a set of responses and chooses factor settings that maximize that score and it is an objective function that ranges from zero outside of the limits of one at the goal. The numerical optimization finds a point that maximizes the desirability function. The characteristics of a goal may be altered by adjusting the weight or importance. For several responses and factors, all goals get combined into one desirability function (Aman et al., 2008). To resolve this type of parameter design problem, an objective function, $\mathrm{F}(\mathrm{x})$, is defined as follows Eq. (7) (Myers et al., 2002; Bouzid et al., 2014a; Routara et al., 2009).

$$
\begin{aligned}
& D F=\left(\prod_{i=1}^{n} d_{i}^{w i}\right)^{1 / n} w i \\
& F(x)=-D F
\end{aligned}
$$

where $d_{i}$ is the desirability defined for the $i^{\text {th }}$ targeted output and $w_{i}$ is the weighting of $d_{i}$. For various goals of each targeted output, the desirability $d_{i}$ can be defined in different forms. 

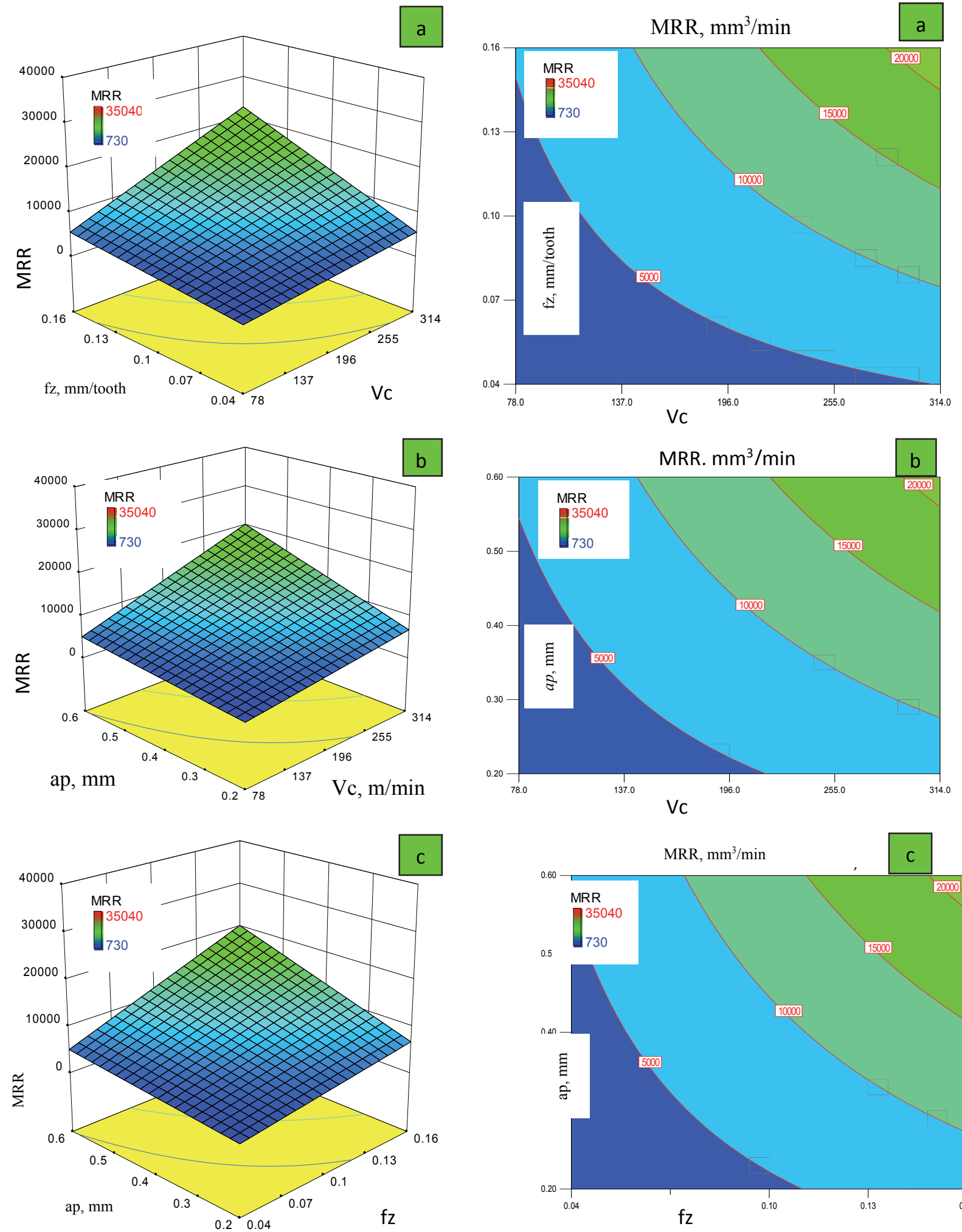

Fig. 8. Response surface for MRR as a function of (Vc, fz), (Vc, ap) and (ap, fz)

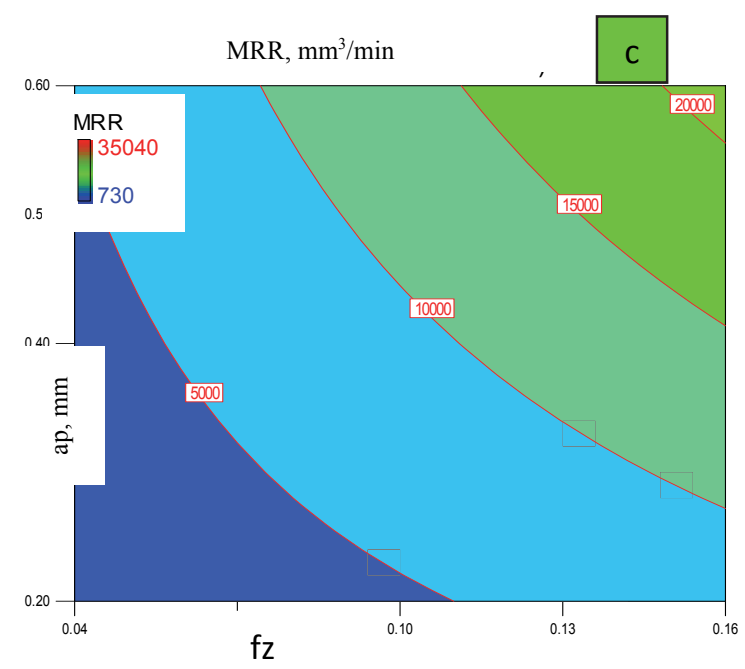

Fig. 9. Contour plot of $M R R=f(V c, f z, a p)$ 
The constraints used during the optimization process are summarized in Table 9. The optimal solutions are reported in Table 10 in order to decrease the desirability level. Fig. 10 and Table 10 show the optimization results. Values of optimal cutting parameters are found to be as follows: Vc $=314 / \mathrm{min}, \mathrm{fz}$ $=0.16 \mathrm{~mm} /$ tooth and ap $=0.6 \mathrm{~mm}$. The optimized criteria surface roughness and Material Removed Rate are as follows: $\mathrm{Ra}=0.709548, \mathrm{Ry}=3.79162, \mathrm{Rz}=3.69408 \mu \mathrm{m}$ and $\mathrm{MRR}=32804.9 \mathrm{~mm}^{3} / \mathrm{min}$. Figs. 11 , 12 and 13 present respectively the contour plot, response surface and the bar graph of composite desirability for the cutting conditions and the responses together with a combined desirability $=0.924$.

Table 9

Constraints for optimization of machining parameters

\begin{tabular}{cccc}
\hline Constraints & Goal & Lower limit & Upper limit \\
\hline$V c, \mathrm{~m} / \mathrm{min}$ & In range & 78 & 314 \\
$f z, \mathrm{~mm} / \mathrm{tooth}$ & In range & 0.04 & 0.16 \\
$a p, \mathrm{~mm}$ & In range & 0.2 & 0.6 \\
$R a, \mu \mathrm{m}$ & Minimize & 0.48 & 2.62 \\
$R y, \mu \mathrm{m}$ & Minimize & 2.85 & 20.55 \\
$R z, \mu \mathrm{m}$ & Minimize & 2.73 & 15.47 \\
$M R R, \mathrm{~mm}^{3} / \mathrm{min}$ & Maximize & 730 & 35040 \\
\hline
\end{tabular}

Table 10

Response optimization for surface roughness and $M R R$

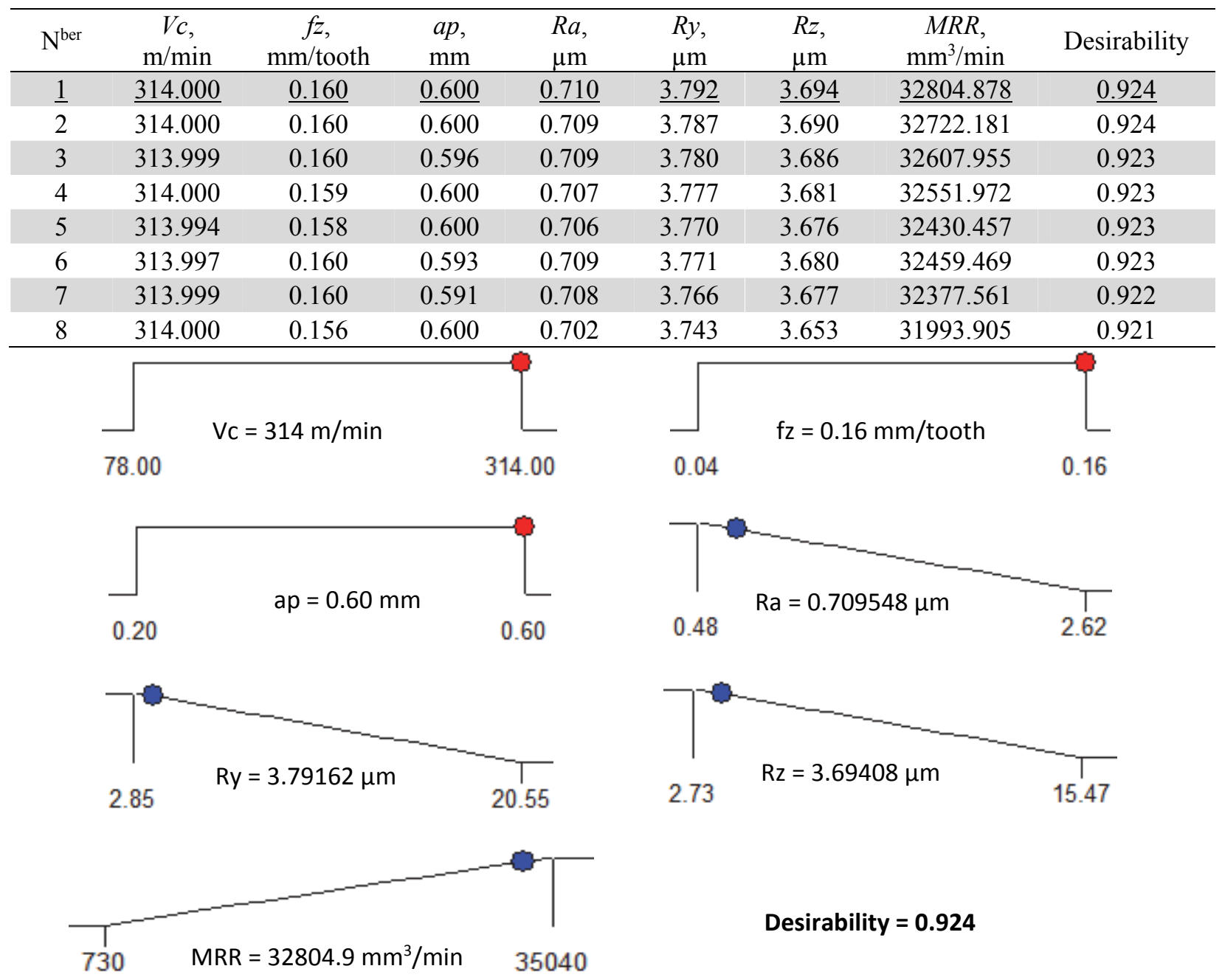

Fig. 10. Ram function graph for surface roughness and Material Removed Rate 


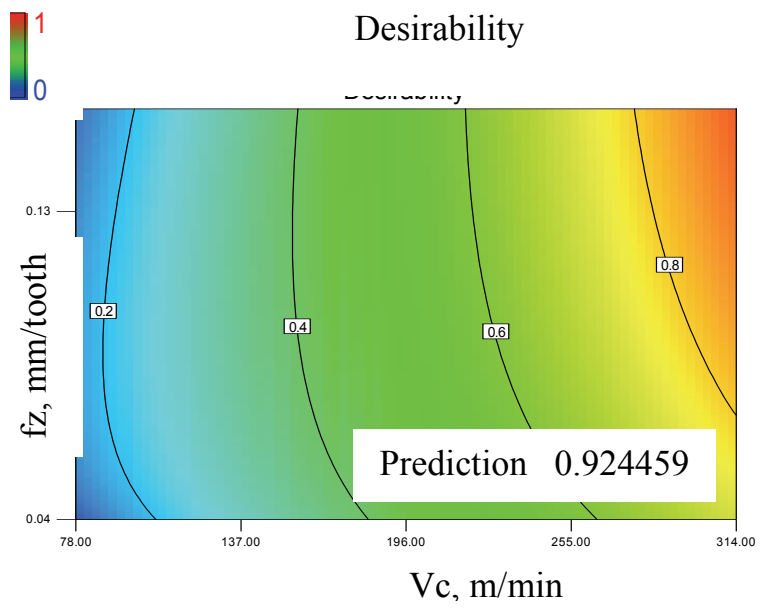

Fig. 11. Contour plot of Composite desirability for $\mathrm{Ra}, \mathrm{Ry}, \mathrm{Rz}$ and MRR

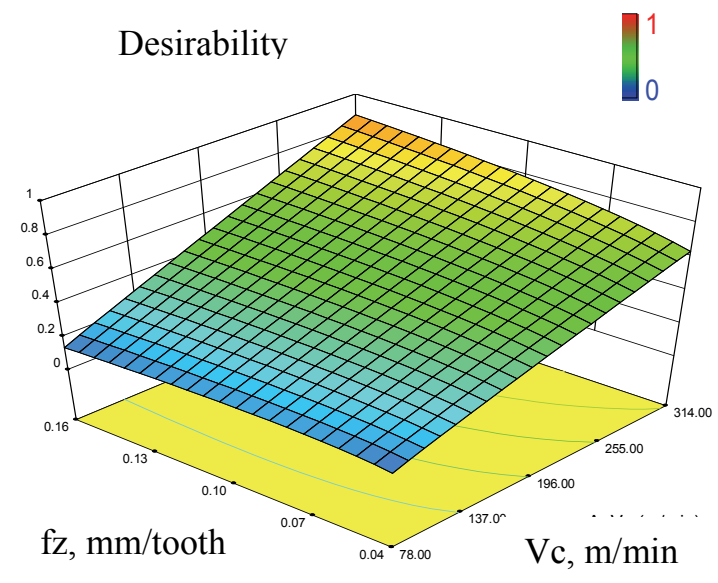

Fig.12 Response surface of Composite desirability for Ra, Ry, Rz and MRR

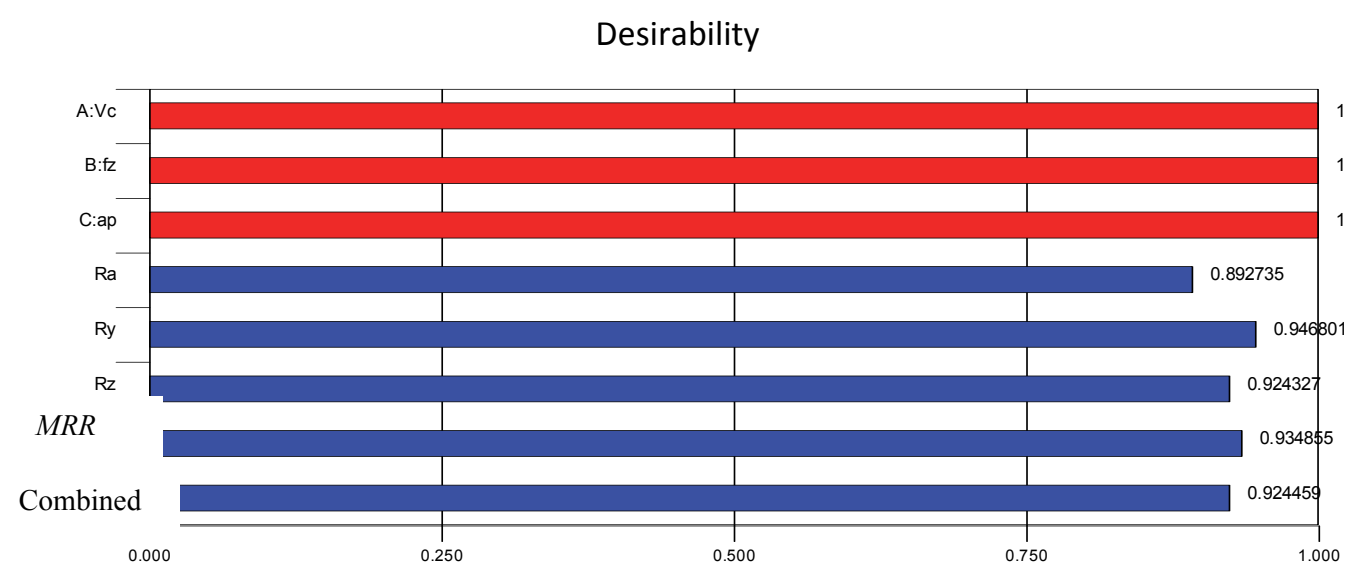

Fig. 13. 3D bar graph of desirability for Ra, Ry, Rz and MRR

\subsection{Flank wear effect on cutting length and roughness}

Fig. 14 shows the evolution of the flank wear (VB) and the maximum flank wear (VBmax) according to the cutting length Lc. The value of wear shown in the curve is the average of the five cutting inserts. The results obtained show that the wear goes through three steps. In the first step the flank wear is relatively accelerated, reaching VB $=0.147 \mathrm{~mm}$ for a cutting length $\mathrm{Lc}=6684 \mathrm{~mm}(501 \mathrm{sec})$; this is explained by the first commissioning of cutting tool, which favors the coating removal and elimination of the asperities at the cutting edges. The second step is the normal wear period, during which the tool travels a total cutting length $\mathrm{Lc}=29960 \mathrm{~mm}(2247 \mathrm{sec})$, it reaches a wear $\mathrm{VB}=0.32 \mathrm{~mm}$. Beyond this point, the temperature in the contact area of the active portion will increase more and more, which promotes the acceleration of the wear mechanism until $\mathrm{VBmax}=0.72 \mathrm{~mm}$ with $\mathrm{Lc}=34000 \mathrm{~mm}$ (2551 Sec). Therefore, the tool loses its cutting qualities then its change becomes indispensable. The tool wear behaviors were also pointed out by Khrais et al. (2007). Excellent scraping edge -line gives it a greater resistance to wear. In the first zone, the results of the Fig. 15 show a significant increase in the surface roughness Ra of the order of $0.6 \mu \mathrm{m}$, for a flank wear $(\mathrm{VB}=0.147 \mathrm{~mm}$ ) after a cutting length $\mathrm{Lc}=6684 \mathrm{~mm}(501 \mathrm{Sec})$. In the second zone corresponding to the normal wear phase, there has been a certain stability of the roughness $R a$, which is of the order of $0.75 \mu \mathrm{m}$ with a flank wear $\mathrm{VB}=0.32 \mathrm{~mm}$, after a total cutting length $\mathrm{Lc}=29960 \mathrm{~mm}(2247 \mathrm{Sec})$, this can be explained by the built up edge on the cutting inserts increasing the curvature radius of the cutting edge and then minimize the depth of the furrows dug on the 
machined surface that improves the surface roughness, the furrows are deeper and broader as the feed rate increases. The Fig. 16 illustrates the morphology of the flank wear from one of cutting inserts at different states.

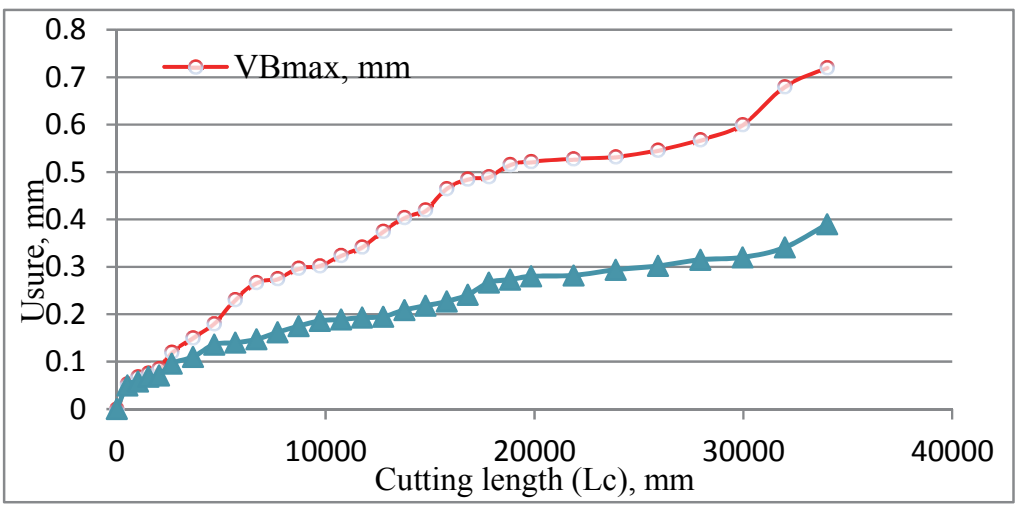

Fig. 14. Flank wear curves when machining at a $439.6 \mathrm{~m} / \mathrm{min}$ and a feed per tooth of $0.114 \mathrm{~mm}$

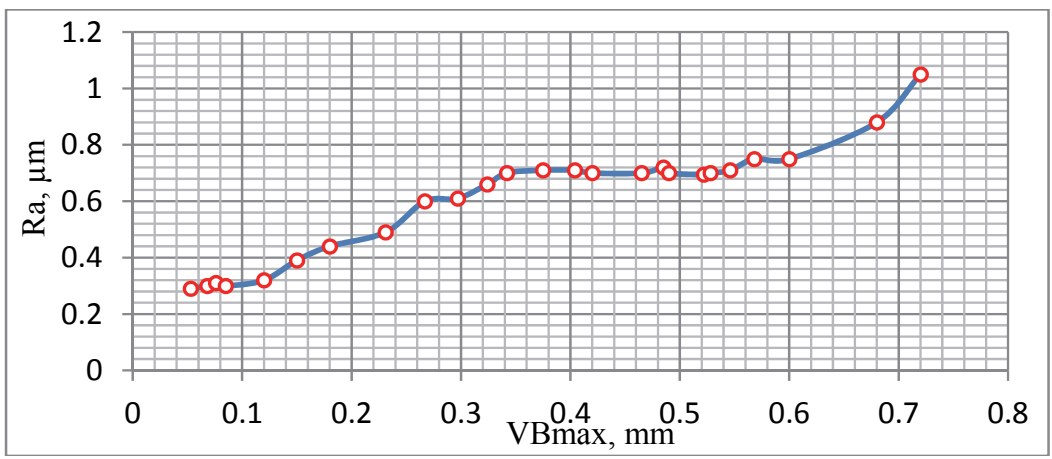

Fig. 15. Flank wear effect on roughness when machining at a $439.6 \mathrm{~m} / \mathrm{min}$ and a feed per of $0.114 \mathrm{~mm}$ tooth
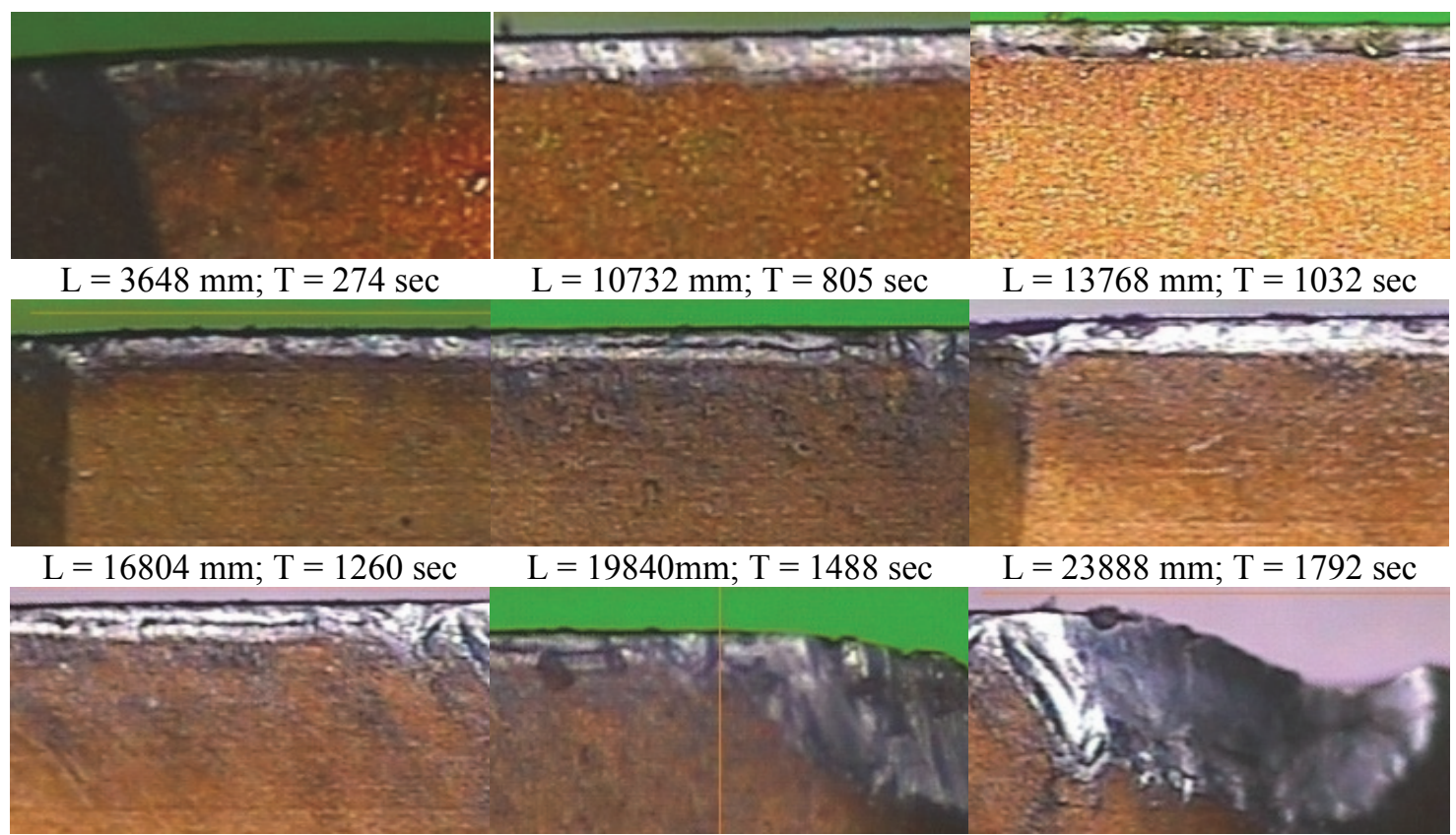

$\mathrm{L}=27936 \mathrm{~mm} ; \mathrm{T}=2095 \mathrm{sec} \quad \mathrm{L}=29960 \mathrm{~mm} ; \mathrm{T}=2247 \mathrm{sec} \quad \mathrm{L}=34008 \mathrm{~mm} ; \mathrm{T}=2551 \mathrm{sec}$

Fig. 16. Micrograph of insert after different machining times 
To visualize the furrows, a representative example of 3D image of milling surface is envisioned by means of isometric view Fig. 17. In the third zone, which begins from $\mathrm{VB}=0.32 \mathrm{~mm}$ is noted that the roughness takes an upward curve again after a certain stability. We noted that until VBmax $=0.6 \mathrm{~mm}$, the surface roughness $\mathrm{Ra}<0.7 \mu \mathrm{m}$ (Yallese et al., 2009).
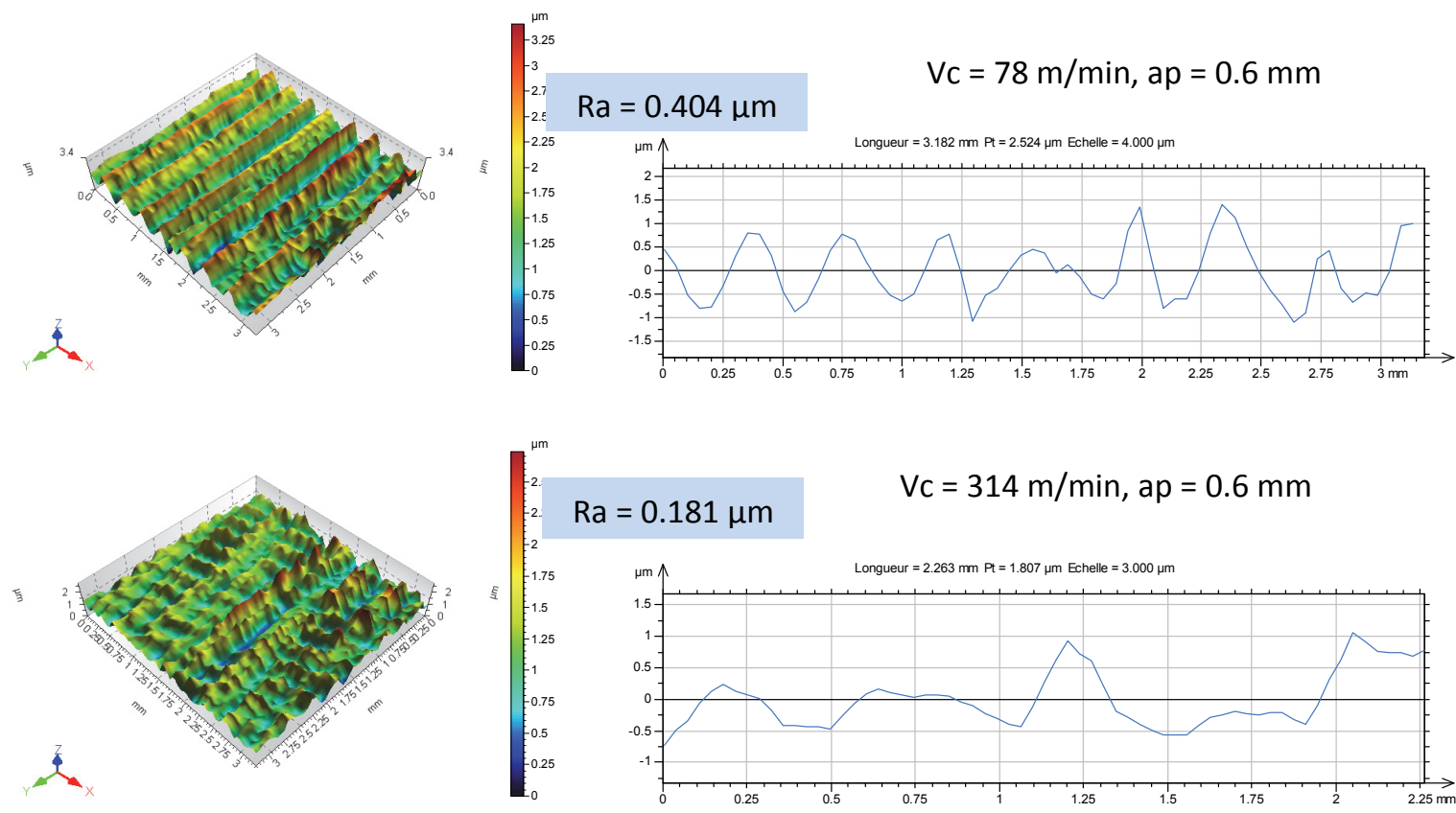

$$
\mathrm{Ra}=0.181 \mu \mathrm{m} \quad \mathrm{Vc}=314 \mathrm{~m} / \mathrm{min}, \mathrm{ap}=0.6 \mathrm{~mm}
$$
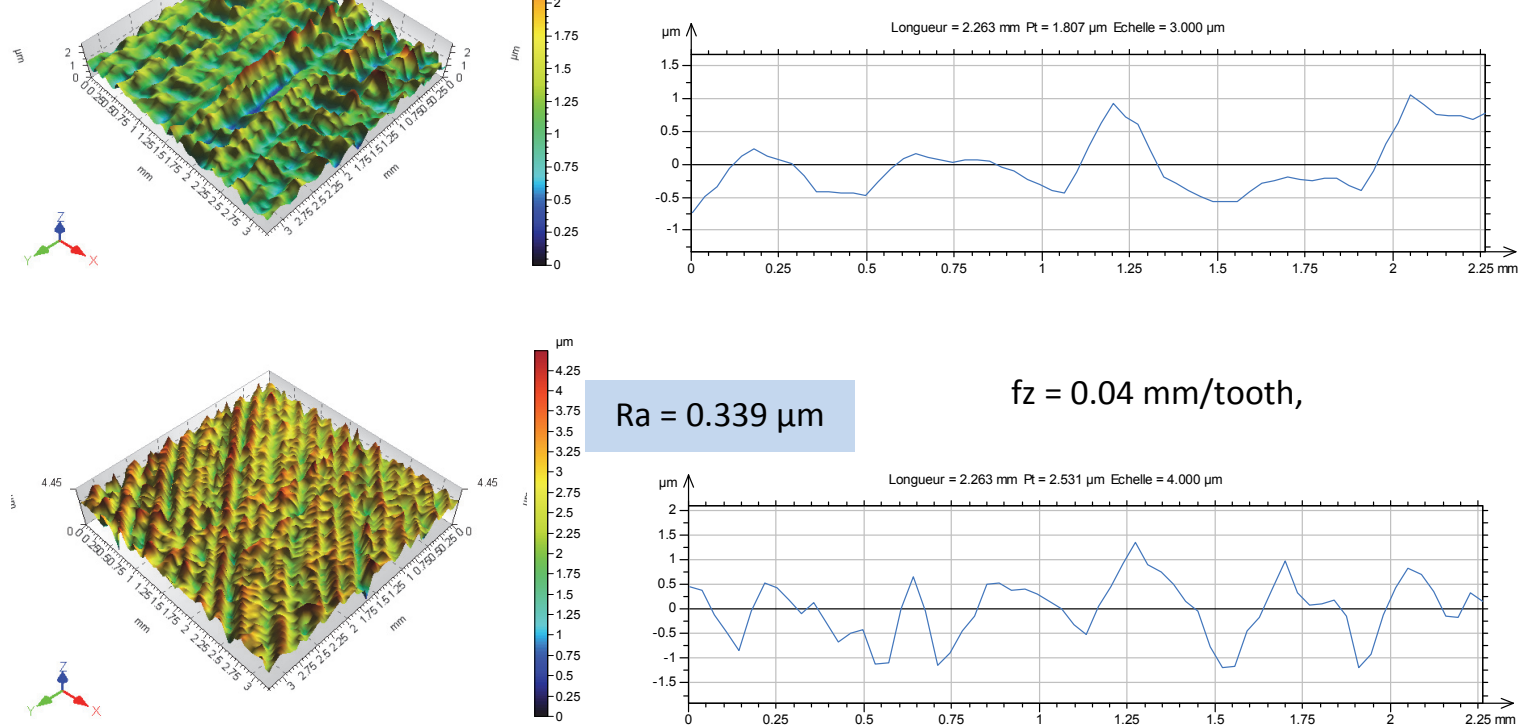

$$
\mathrm{Ra}=0.339 \mu \mathrm{m} \quad \mathrm{fz}=0.04 \mathrm{~mm} / \text { tooth, }
$$
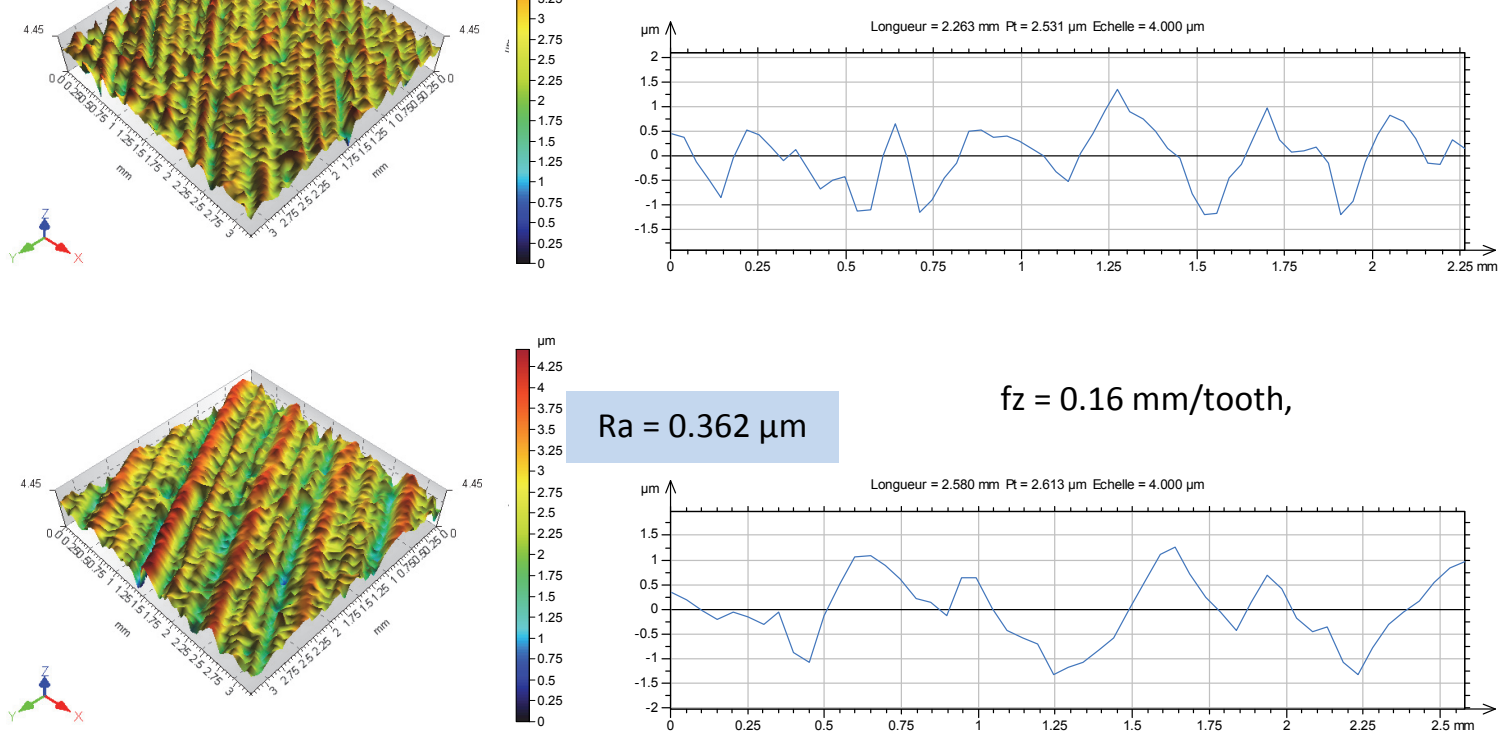

Fig. 17. 3D surface topography for (Ra) 


\section{Conclusions}

The face milling tests of the AISI 1040 steel, using the coated carbide insert GC1030 has been investigated in order to develop statistical models of surface roughness criteria. These models were obtained using multiple linear regression and response surface methodology. The evaluation of coefficients of determination and mathematical models allowed us the examination of the influence degree of the various cutting parameters (cutting speed, feed per tooth and depth of cut) on different roughness criteria (Ra, Ry, Rz) and on the Material Removed Rate during the face milling process.

From the results and the analysis obtained, it can be concluded that the:

1) Cutting speed $(\mathrm{Vc})$ has a significant impact on various criteria roughness studied ( $R y, R z$ and $R a)$ with contributions of $95.51 \%, 86.74 \%$ et $92.20 \%$ respectively, this is due to the geometry of the insert which has a scrapping edge which enables to obtain low roughness even at important feed rate.

2) Cutting speed (Vc) and the feed per tooth (fz) are the most influential parameters on the Material Removed Rate with a contribution of $30.76 \%$ followed by depth of cut with $17.94 \%$.

3) The analysis of the results shows that the mathematical model of the Material Removed Rate was the most representative model because its coefficient of determination $\mathrm{R}^{2}$ was $98.53 \%$, followed by the model of Ra with $\mathrm{R}^{2}$ of $97.67 \%$, followed by the model Ry with $95.23 \%$ and $\mathrm{Rz}$ was the last model with $93.15 \%$.

4) The experimental and predicted values were very close to each other; the developed mathematical models could be effectively utilized in face milling.

5) Based on the response surface optimization and the composite desirability method of RSM, the optimal cutting parameters of AISI 1040 steel with coated carbide tool have beeb found to be as follows: $\mathrm{Vc}=314 \mathrm{~m} / \mathrm{min}, \mathrm{fz}=0.16 \mathrm{~mm} /$ tooth and $\mathrm{ap}=0.6 \mathrm{~mm}$. The optimized responses are $\mathrm{Ra}=$ $0.709548, \mathrm{Ry}=3.79162, \mathrm{Rz}=3.69408 \mu \mathrm{m}$ and $\mathrm{MRR}=32804.9 \mathrm{~mm}^{3} / \mathrm{min}$, with a composite desirability of 0.924 .

6) At $\mathrm{Vc}=439.6 \mathrm{~m} / \mathrm{min}, \mathrm{fz}=0.114 \mathrm{~mm} /$ tooth and ap $=0.6 \mathrm{~mm}$. The tool life of the insert is $2247 \mathrm{sec}$ with total cutting length $\mathrm{Lc}=29960 \mathrm{~mm}$.

7) We noted that until VBmax $=0.6 \mathrm{~mm}$, the surface roughness $\mathrm{Ra}<0.7 \mu \mathrm{m}$

\section{Acknowledgments}

This work was achieved in the laboratory LMS (Guelma University, Algeria). The authors would like to thank the Algerian Ministry of Higher Education and Scientific Research (MESRS) and the Delegated Ministry for Scientific Research (MDRS) for providing financial support through CNEPRU Research Project, Code: 0301520080027 (University 08 May 1945, Guelma).

\section{References}

Aman, A., Hari, S., Pradeep, K., \& Manmohan, S. (2008). Optimization of multiple quality characteristics for CNC turning under cryogenic cutting environment using desirability function. Journal of Materials Processing Technology, 205(1-3), 42-50.

Aouici, H., Fnides, B., Elbahc, M., Benlahmidia, S. Bensouilah, H., \& Yallese, M. A. (2016). Surface roughness evaluation of various cutting materials in hard turning of AISI H11. International Journal of Industrial Engineering Computations, 7(2), 339-352. 
Aouici, H., Bouchelaghem, H., Yallese, M.A., Elbah, M. \& Fnides, B. (2014). Machinability investigation in hard turning of AISI D3 cold work steel with ceramic tool using response surface methodology. Internatioanl Journal of Advanced Manufacturing Technology, 73(9), 1775-1788.

Aouici, H., Yallese, M.A., Belbah, A., Ameur, M.F., \& Elbah, M. (2013). Experimental investigation of cutting parameters influence on surface roughness and cutting forces in hard turning of X38CrMoV51 with CBN tool. Sadhana, 38(3), 429-445.

Barua, M.K., \& Rao, J.S. (2010). Measurement surface roughness through RSM: effect of coated carbide tool on 6061-t4 aluminum. International Journal of Enterprise Network Management (IJENM), 4(2), 136-153.

Bhaumik, M., \& Maity, K. (2017). Effect of machining parameter on the surface roughness of AISI 304 in silicon carbide powder mixed EDM. Decision Science Letters, 6(3), 261-268.

Bhuyan, R., \& Routara, B. (2016). Optimization the machining parameters by using VIKOR and Entropy Weight method during EDM process of Al-18\% SiCp Metal matrix composite. Decision Science Letters, 5(2), 269-282.

Bouacha, K., Yallese, M.A., Khamel, S., Belhadi, S. (2014). Analysis and optimization of hard turning operation using cubic boron nitride tool. International Journal of Refractory Metals and Hard Materials, 45, 160-178.

Bouzid, L., Boutabba, S., Yallese, M.A, Belhadi, S., Girardin, F. (2014a). Simultaneous optimization of surface roughness and material removal rate for turning of $\mathrm{X} 20 \mathrm{Cr} 13$ stainless steel. International Journal of Advanced Manufacturing Technology, 74 (5), 879-891.

Bouzid, L., Yallese, M. A., Belhadi, S., Mabrouki, T., \& Boulanouar, L. (2014). RMS-based optimisation of surface roughness when turning AISI 420 stainless steel. International Journal of Materials and Product Technology, 49(4), 224-251.

Bouzid, L., Yallese, M. A., Chaoui, K., Mabrouki, T., \& Boulanouar, L. (2015). Mathematical modeling for turning on AISI 420 stainless steel using surface response methodology. Proceedings of the Institution of Mechanical Engineers, Part B: Journal of Engineering Manufacture, 229(1), 45-61.

Da Silva, R.B., Vieira, J.M., Cardoso, R.N., Carvalho, H.C., Costa, E.S., Machado, A.R.,. De Ávila, R.F. (2011). Tool wear analysis in milling of medium carbon steel with coated cemented carbide inserts using different machining lubrication/cooling systems. Wear, 271(9-10), 2459-2465.

Doniavi, A., Eskanderzade, M., Tahmsebian, M. (2007). Empirical modeling of surface roughness in turning process of 1060 steel using factorial design methodology. Journal of Applied Sciences, 7(17), 2509-2513.

Bagci, E., \& Aykut, Ş. (2006). A study of Taguchi optimization method for identifying optimum surface roughness in CNC face milling of cobalt-based alloy (stellite 6). The International Journal of Advanced Manufacturing Technology, 29(9-10), 940-947.

Fnides, B., Boutabba, S., Fnides, M., Aouici, H., \& Yallese, M.A. (2013). Cutting tools flank wear and productivity investigation in straight turning of X38CrMoV5-1 (50 HRC). International Journal of Applied Engineering and Technology, 3(1), 1-10.

Fnides, B., Yallese, M.A., Mabrouki, T., \& Rigal, J.F. (2009). Surface roughness model in turning hardened hot work steel using mixed ceramic tool. Mechanika, 3(77), 68-73.

John, B. (2013). Application of desirability function for optimizing the performance characteristics of carbonitrided bushes. International Journal of Industrial Engineering Computations, 4(3), 305-314.

Hessainia, Z., Belbah, A., Yallese, M.A., Mabrouki, T., \& Rigal, J.F. (2013). On the prediction of surface roughness in the hard turning based on cutting parameters and tool vibrations.Measurement, 46(5), 1671-1681.

Hessainia, Z., Yallese, M.A., Bouzid, L., \& Mabrouki, T. (2015). On the application of response surface methodology for predicting and optimizing surface roughness and cutting forces in hard turning by PVD coated insert. International Journal of Industrial Engineering Computations, 6(2), 267-284.

Huang, L., \& Chen, J.C. (2001). A multiple regression model to predict in-process surface roughness in turning operation via accelerometer. Journal of Industrial Technology, 17(2), 1-8.

Keblouti, O., Boulanouar, L., Azizia, M. W., \& Yallese, M. A. (2016). Modeling and multi-objective optimization of surface roughness and productivity in dry turning of AISI 52100 steel using (TiCN- 
TiN) coating cermet tools. International Journal of Industrial Engineering Computations, 8(1), 7184.

Kadirgama, K., Noor, M.M., Rahman, M.M., Rejab, M.R.M., Haron, C.H.C., \& Abou-El-Hossein, K.A. (2009). Surface Roughness Prediction Model of 6061-T6 Aluminium Alloy Machining Using Statistical Method. European Journal of Scientific Research, 25(2), 250-256.

Kevin Chou, Y., Evans, C.J., \& Barash, M.M. (2003). Experimental investigation on cubic boron nitride turning of hardened AISI 52100 steel. Journal of Materials Processing Technology, 134(1), 1-9.

Khairi, Y., Nukman, Y., Yusof, T.M., Dawal, S.Z., Qin Yang, H., Mahlia, T.M.I., \& Tamrin, K.F. (2010). Effect of cutting parameters on the surface roughness of titanium alloys using end milling process. Scientific Research and Essays, 5(11), 1284-1293.

Khrais, S.K., \& Lin, Y.J. (2007). Wear mechanisms and tool performance of TiAlN PVD coated inserts during machining of AISI 4140 steel. Wear, 262(1-2), 64-69.

Meddour, I., Yallese, M. A., Khattabi, R., Elbah, M., \& Boulanouar, L. (2015). Investigation and modeling of cutting forces and surface roughness when hard turning of AISI 52100 steel with mixed ceramic tool: cutting conditions optimization. The International Journal of Advanced Manufacturing Technology, 77(5-8), 1387-1399.

Mohapatraa, K., Satpathya, M., \& Sahooa, S. (2017). Comparison of optimization techniques for MRR and surface roughness in wire EDM process for gear cutting. International Journal of Industrial Engineering Computations, 8(2), 251-262.

Myers, R.H., \& Montgomery, D.C. (2002). Response surface methodology: process and product optimization using designed experiments. 2nd ed. John Wiley and Sons, Inc.: New York,

Nayak, I., Rana, J., \& Parida, A. (2017). Performance optimization in electro-discharge machining using a suitable multiresponse optimization technique. Decision Science Letters, 6(3), 283-294.

Oktem, H., Erzurumlu, T., \& Kurtaran, H. (2005). Application of response surface methodology in the optimization of cutting conditions for surface roughness. Journal of Materials Processing Technology, 170(1-2), 11-16.

Panda, A., Sahoo, A., \& Rout, R. (2016). Multi-attribute decision making parametric optimization and modeling in hard turning using ceramic insert through grey relational analysis: A case study. Decision Science Letters, 5(4), 581-592.

Patel, K.M., \& Joshi, S.S. (2006). Mechanics of machining of face-milling operation performed using a self-propelled round insert milling cutter. Journal of Materials Processing Technology, 171(1), 6876.

Richetti, A., Machado, A. R., Da Silva, M. B., Ezugwu, E. O., \& Bonney, J. (2004). Influence of the number of inserts for tool life evaluation in face milling of steels. International Journal of Machine Tools and Manufacture, 44(7), 695-700.

Routara, B. C., Bandyopadhyay, A., \& Sahoo, P. (2009). Roughness modeling and optimization in CNC end milling using response surface method: effect of workpiece material variation. The International Journal of Advanced Manufacturing Technology, 40(11-12), 1166-1180.

Tebassi, H., Yallese, M., Khettabi, R., Belhadi, S., Meddour, I., \& Girardin, F. (2016). Multi-objective optimization of surface roughness, cutting forces, productivity and Power consumption when turning of Inconel 718. International Journal of Industrial Engineering Computations, 7(1), 111-134.

Sahoo, A.K., \& Mishra. P.C. (2014). A response surface methodology and desirability approach for predictive modeling and optimization of cutting temperature in machining hardened steel. International Journal of Industrial Engineering Computations, 5(3), 407-416.

Yallese, M.A., Chaoui, K., Zeghib, N., Boulanouar, L. \& Rigal, J.F. (2009). Hard machining of hardened bearing steel using cubic boron nitride tool. Journal of Materials Processing Technology, 209(2), 1092-1104. 
(C) 2017 by the authors; licensee Growing Science, Canada. This is an open access article distributed under the terms and conditions of the Creative Commons Attribution (CCBY) license (http://creativecommons.org/licenses/by/4.0/). 